\title{
ORDEM GLOBAL E ACUMULAÇÃO POR DESAPROPRIAÇÃO. A EXPORTAÇÃO DE “ÁGUA VIRTUAL” E A PEGADA HÍDRICA DA MINERAÇÃO DOS METAIS NA ARGENTINA (1997-2014)
}

\author{
Sebastián Gómez Lende ${ }^{1}$
}

\begin{abstract}
Resumo: Orientado a reestruturar os papéis dos países e dos lugares em função dos interesses do capital, a ordem global é um arranjo social econômico, político e territorial hegemônico com base na acumulação por desapropriação. Coordenado e concretizado por corporações transnacionais e apoiado pelos governos dos países periféricos, este espólio é expresso em uma infinidade de formas e facetas: entre eles estão o aumento crescente do extrativismo na América Latina, um fenômeno que desperta crescente preocupação devido tanto à degradação, como à extração e à transferência para o estrangeiro de intangívels ambientais como a "água virtual". À luz desta situação, o presente trabalho tem por objetivo analisar o relativamente recente boom da mega-mineração de metais a céu aberto na Argentina, visando cumprir dois objetivos complementares: avaliar a pegada hídrica desta atividade e o papel que ela desempenha nas exportações nacionais de 'água virtual', bem como levar em conta o impacto social e ambiental das estratégias de apropriação dos recursos hídricos desenvolvidos pela mineração transnacional (e legitimadas pelo Estado), demonstrando as suas ligações com o problema do agravamento do acesso a esse vital elemento sofrido pelas províncias envolvidas.
\end{abstract}

Palavras-chave: Acumulação por desapropriação. "Água virtual". Pegada hídrica. Mineração de metais. Argentina.

\section{Introducción}

Orientado a reestructurar las funciones de países y lugares en función de los intereses del capital, el orden global constituye un arreglo social, económico, político y territorial hegemónico basado en la acumulación por desposesión. Coordinado y concretado por las empresas transnacionales, y avalado por los gobiernos de los países periféricos, ese saqueo se expresa en el creciente auge ganado por el extractivismo en América Latina, y en ese contexto, en la degradación, expoliación y transferencia al exterior de intangibles ambientales. A la luz de esa situación, este trabajo tiene por objetivo analizar el relativamente reciente boom de la megaminería metalífera a cielo abierto en la Argentina, persiguiendo dos objetivos complementarios: evaluar la huella hídrica de la actividad y el papel que ésta desempeña en las 'exportaciones' nacionales de 'agua virtual'; y dar cuenta del impacto social y ambiental de las estrategias de apropiación del recurso hídrico desplegadas por las mineras transnacionales (y legitimadas por el Estado), demostrando incidencia en el agravamiento de la problemática de acceso al vital elemento que sufren las provincias implicadas.

Se elucida, en primer lugar, el soporte teórico que sustenta al trabajo, atendiendo a conceptos básicos como espacio geográfico, orden global, verticalidades, acumulación y por desposesión y extractivismo. A continuación, se definen las nociones de 'intangible ambiental', 'agua virtual' y 'huella hídrica', discutiendo sus implicancias respecto de la reestructuración de la división internacional del trabajo y la acumulación por desposesión, y describiendo la magnitud empírica de los flujos de agua virtual a escala internacional, su distribución según países y el papel desempeñado en ese marco por la Argentina. En tercer lugar, se presenta una breve aproximación al auge de la minería metalífera en Argentina, analizando sus vínculos con el orden global, explicitando la normativa que regula al sector y describiendo sus características generales (inversiones, origen geográfico de las empresas, yacimientos en operación, niveles de rentabilidad), y dando cuenta del creciente nivel de conflictividad social, territorial, política y ambiental que la actividad ha despertado. Se desarrolla luego el núcleo del trabajo, donde se abordan 
pormenorizadamente los nexos entablados entre el boom minero y la problemática hídrica en la Argentina: allí se describe el sistema de producción utilizado por las empresas y los usos que se le asignan al agua para el desarrollo de la actividad, se explica la apropiación (desposesión), depredación y contaminación del recurso hídrico llevadas a cabo por las mineras, se evalúa la huella hídrica y los flujos de agua virtual asociados a la actividad (en términos generales y discriminados por yacimientos $y$ provincias), se calcula el valor económico de esas transferencias, se analiza su incidencia respecto del agravamiento de la crisis hídrica que atraviesan las provincias mineras, y se revela la estrategia desplegada por las empresas transnacionales, orientada a permitir que los países centrales externalicen a la periferia del sistema capitalista las graves implicancias ambientales que entraña la actividad y alivien el nivel de presión ejercido sobre sus propios recursos hídricos. Finalmente, se presentan las conclusiones del trabajo.

2 Orden global y acumulación por desposesión: la división internacional del trabajo y los usos extractivos del territorio

Si el espacio geográfico constituye una forma-contenido expresada a partir de un conjunto solidario, indisociable $y$ contradictorio de sistemas de objetos y sistemas de acciones mediados por normas una amalgama entre configuración territorial y dinámica social- (SANTOS, 1996a), la noción de territorio puede ser definida como ese mismo espacio explicado a partir de sus usos (SANTOS; SILVEIRA, 2001). En el período histórico actual -el medio técnicocientífico-informacional-, los usos del espacio expresan una aceleración de todas las formas de circulación, la consolidación de la división socio-espacial del trabajo, el mayor nivel de especialización económica regional y la diferenciación local según su productividad espacial -su capacidad de rentabilizar una producción dada-, generando una creciente tensión entre globalidad y localidad (SANTOS, 1996a; 1996b).

Opera en ese sentido un orden global, en tanto que arreglo social, económico, político y territorial hegemónico que rediseña países y lugares en función de los intereses del capital; para ello se vale de lo que Santos (1996a) llama verticalidades, esto es, solidaridades organizacionales, externas, que obligando a la realización de cambios estructurales y funcionales, crean desorden en el ámbito local, a la vez que imponen estricta obediencia a la racionalidad del mercado y los agentes dominantes. Sus atributos -mundialización del capital, producción globalizada, actividades modernas, normas internacionales(SANTOS, 1996a; 1996b; 2000), implican el uso del territorio como mero recurso (GOTTMANN, 1975; HAESBAERT, 2008), permitiendo a esas fuerzas verticales racionalizar o hacer tabla rasa de la historia pretérita y sus herencias espaciales (SILVEIRA, 1999).

Santos y Silveira (2001) explican que, en la actualidad, los usos modernos del territorio son racionales únicamente para los agentes que se benefician con ese modelo de organización espacial, pero irracionales para todos los demás actores; esto ocurre porque, en la inmensa mayoría de los casos, se trata de formas de explotación que vertebran el eje estructural de lo que Harvey (2004) llama 'acumulación por desposesión'. Si por acumulación primitiva u originaria se entiende el acto histórico de despojo violento que instauró las relaciones sociales capitalistas a escala mundial -vía el descubrimiento y explotación de las minas auríferas y argentíferas de América, el trabajo forzado y exterminio de la población nativa, la caza y venta de esclavos en África, la conquista de las Indias Orientales, la apropiación de bienes de la Iglesia y el cercamiento de tierras comunales en favor de la nobleza británica-, coadyuvando así a formar el stock de capital necesario para la Revolución Industrial europea (MARX, 1968), la acumulación por desposesión no es más que la posterior continuidad y perfeccionamiento de ese mecanismo.

Obligando al capital a disponer siempre de un fondo exterior de activos (tierras 'vacías', nuevos mercados y fuentes de recursos) -o bien, si éste no existe, crearlo de algún modo-, las crisis cíclicas de hiperacumulación exigen la búsqueda de 'soluciones' o 'ajustes espacio-temporales' basados en el imperialismo; de ahí que el saqueo se haya convertido en una fuerza permanente de la geografía histórica del capitalismo mundial, a tal punto que en la actualidad es su forma de acumulación más importante (HARVEY, 2004). Otros mecanismos de desposesión se añaden, pues, a los tradicionales (monetarización, tributación, usura, endeudamiento, 
v.17, n. 2, p. 6-28, jul./dez. 2015

penetración del capital en el sector agropecuario, etc.). Sobresalen, en tal sentido, fenómenos como la mercantilización y privatización de la tierra, la expulsión de campesinos e indígenas de sus dominios ancestrales, la privatización de firmas estatales industriales y de servicios públicos, la conversión de regímenes de propiedad común al régimen de propiedad privada, la depredación y degradación a gran escala del patrimonio ambiental y los recursos naturales, y la biopiratería, el robo de los recursos genéticos y los derechos de propiedad intelectual a ellos asociados (HARVEY, 2004).

So pretexto de modernidad, progreso e inserción en los mercados externos, la acumulación por desposesión es una estrategia ampliamente desplegada en aras de arrebatarle deliberadamente a sociedades y territorios sus recursos más valiosos. No es extraño que en los países periféricos se asista al advenimiento y consolidación de un modelo o patrón espacial casi exclusivamente basado en la producción limitada de 'racionalidad' -el orden de prioridades que beneficia a los actores hegemónicos- y la producción ilimitada de 'irracionalidad' o escasez -la insatisfacción de las necesidades esenciales de todos los demás agentes, agravando la problemática social- (SANTOS, 1996a). Todas las formas de acumulación por desposesión se estructuran y expanden a través de la división internacional del trabajo, que asigna a países y lugares diversas funciones de producción y consumo, según un complejo entramado de factores sociales, económicos, políticos y ambientales. Solapada con la tradicional división entre 'centros' y 'periferias', la relativamente reciente oposición planteada entre el 'Norte global' y el 'Sur global' revela que las actividades desarrolladas en este último ya no se limitan a ser intensivas en capital, con bajos niveles de empleo, salarios y valor agregado, y mayoritariamente controladas por el capital extranjero, sino que además operan a través de mecanismos más sutiles de subordinación y despojo: el saqueo de los recursos naturales, el incremento exponencial de la degradación y destrucción ambiental, la intensificación del ritmo de transferencia de capacidad de carga y servicios ecológicos hacia los países centrales y la implementación de sistemas/métodos de explotación/producción prohibidos por las legislaciones ambientales del Norte, operan imponiendo al Sur el papel de amortiguador ambiental de los excesos del sistema capitalista mundial (GUDYNAS, 2009; FRECHERO, 2013).

Los usos extractivos del territorio son, ciertamente, protagonistas privilegiados de la actual fase de acumulación por desposesión. Omnipresente en América Latina, el extractivismo constituye un patrón signado por la estructuración de una matriz socio-productiva escasamente diversificada, altamente dependiente de la explotación intensiva de recursos naturales y la apropiación o usufructo de los productos así obtenidos por parte de agentes externos, vía la exportación (FRECHERO, 2013). Siendo un modelo hegemónico planeado para ser indiferente a su entorno (SANTOS, 2000), el extractivismo implanta economías de enclave y 'zonas de sacrificio' que perpetúan y agravan la problemática socio-ambiental de América del Sur, a la vez que garantizan la continuidad de su inserción subordinada en el marco de la globalización comercial y financiera (GUDYNAS, 2011). El auge (neo)extractivista se encuentra íntimamente relacionado con otro fenómeno de acumulación por desposesión: el 'comercio' internacional de 'agua virtual.

3 El 'comercio' mundial de 'agua virtual': conceptos básicos y el caso de la Argentina

En El Capital, Marx (1968) acuñó el concepto de "fetichismo de la mercancía" para dar cuenta del enmascaramiento de las relaciones sociales que subyacen a la producción capitalista y el ocultamiento de las condiciones bajo las cuales el producto ha sido engendrado (HARVEY, 1990). Sin embargo, sus implicancias rebasan ampliamente la esfera laboral -el ámbito para el cual fue originalmente pensado y aplicado el concepto- para dar cuenta también de las condiciones eminentemente políticas $y$ ambientales de la acumulación capitalista; al igual que un obrero que es alienado del producto que contribuyó a fabricar, la sociedad nacional suele desconocer el derrotero y destino del excedente que se escurre fuera de sus fronteras (GÓMEZ LENDE, 2010), en tanto también ignora las formas de explotación socio-laboral y las condiciones políticas $y$, sobre todo, ambientales, que precedieron (e hicieron posible) la producción de una mercancía dada. 
En este último campo, la reciente preocupación académica y política por el estudio de los denominados 'intangibles ambientales' (PENGUE, 2012) viene a desmontar otros aspectos derivados de ese fetichismo, arrojando luz sobre el funcionamiento de mecanismos de acumulación por desposesión hasta entonces no considerados. Los intangibles ambientales son aquellos bienes o recursos de base sin los cuales sería prácticamente imposible desarrollar cualquier producción, y que proporcionan valiosos servicios ambientales por los cuales la economía global nada paga, pues no han sido incluidos formalmente en los balances de ganancias y pérdidas ni de las empresas ni de los países (PENGUE, 2012). Las nociones de 'suelo virtual' (PENGUE, 2010) o 'agua virtual' (ALLAN, 1993) constituyen ejemplos del concepto de intangible ambiental, en tanto apuntan a identificar y cuantificar el flujo de nutrientes edáficos o recursos hídricos que, al migrar al exterior incorporados a alimentos, minerales, manufacturas $y$ commodities, convierten a los países especializados en dichas funciones en proveedores de biomasa global; los recursos así expoliados y transferidos vía comercio internacional a los países centrales dejan tras de sí abultados pasivos ambientales que engrosan la deuda ecológica que el Norte históricamente ha acumulado a expensas del Sur (MARTÍNEZ ALIER; OLIVERAS, 2003). Originalmente propuesto por Allan (1993) para explicar las estrategias comerciales de los países áridos de África y Medio Oriente, el concepto de 'agua virtual' (virtual water) alude al volumen total de recursos hídricos requerido como insumo en los procesos de producción de los diferentes tipos de mercancías; en otras palabras, se trata del agua 'contenida' -más bien condensada- en un bien final objeto de comercio. El agua virtual debe ser entendida como acumulativa, pues los recursos hídricos consumidos por la fabricación de bienes industriales se añaden en el cálculo final al agua demandada por la elaboración de los productos primarios que fueron utilizados como insumos por aquellos. EI concepto revela las asimetrías derivadas de los mecanismos mediante los cuales esa suerte de 'agua exógena' es transferida y distribuida entre países vía flujos de exportación e importación (HOEKSTRA; HUNG, 2002; ZIMMER; RENAULT, 2003; ROCHA FELICES, 2012; GRAJALES QUINTERO; JARAMILLO ROBLEDO; CRUZ
CERÓN, 2008; MACHADO ARAOZ, 2010; PARADA-PUIG, 2012). Años después, Hoekstra y Hung (2002) acuñaron el concepto de 'huella hídrica' (water footprint) como reflejo de la sumatoria del consumo doméstico y la importación de agua virtual de un determinado país, actividad económica o grupo de personas para la producción de aquellos bienes y servicios que consumen; indicador útil de la demanda nacional, agropecuaria e industrial de agua, la huella hídrica es tanto interna -el volumen de agua utilizado para satisfacer el consumo doméstico- como externa -los recursos hídricos de otros países que son transferidos vía la importación de bienes intensivos en agua, aliviando así la presión ejercida sobre la propia disponibilidad del vital elemento $y$, en consecuencia, externalizando esa carga a terceros- (LLAMAS MADURGA, 2005; GRAJALES QUINTERO; JARAMILLO ROBLEDO; CRUZ CERÓN, 2008; COLLADO; SAAVEDRA, 2010).

Sin ser un fenómeno nuevo, el flujo de agua virtual existe desde el propio origen del comercio. Machado Araoz (2010) explica que la transición al capitalismo representó también el pasaje de una cosmovisión estructurada en torno al 'agua sagrada' a otra semiología: la del 'agua científica'. Con el imperativo de la expansión industrial, aparece el uso del agua como medio de producción para otras mercancías; y al ser destinada a las actividades de mayor rendimiento económico -agricultura, extracción de minerales, producción de energía eléctrica, ramas manufactureras-, en vez de hacerlo en función de su utilidad social o prioridad ambiental, el agua se convierte en una mercancía más, comercializándose no sólo directamente, sino también (y principalmente) de modo encubierto, enmascarado bajo el sustrato que supone el intercambio de otras mercancías. Lo anterior encierra profundas implicaciones económicas, filosóficas y políticas. En el sentido marxista del término, el agua se ha metamorfoseado en una forma de capital fijo $^{2}$, y como tal, se halla en permanente circulación, desgastándose al transferir parte de su valor al producto final: fluye constantemente como valor de cambio, sin abandonar como valor de uso la esfera de la producción (HARVEY, 1988). En ese mismo sentido, Santos (1996a) afirma que

\footnotetext{
${ }^{2}$ Se entiende por capital fijo a cualquier instrumento de trabajo intercambiado y consumido productivamente como mercancía dentro del proceso de creación de la plusvalía (HARVEY, 1988).
} 
los fijos -los objetos o formas geográficas de la configuración territorial o materialidad del espacio- operan paralelamente como flujos, pues circulan transmitiendo valor a las actividades que los utilizan. Obstando las visibles obras de ingeniería que modifican materialmente la distribución social y geográfica del agua, cuando ésta es usada para la producción de un determinado bien y fluye socialmente a través del circuito comercial de ese producto, los movimientos que se trazan y concretan en la esfera del mercado determinan políticamente los mecanismos reales de asignación del recurso hídrico, más allá de su dotación y el reparto inicial (MACHADO ARAOZ, 2010).

Otrora inadvertidos, esos flujos han pasado a formar parte del eje estratégico de interrelaciones forjado entre la depredación de bienes comunes y la mercantilización de la naturaleza, engendrando así nuevas formas de desigualdad y expropiación a escala global; en ese esquema, el agua virtual tiene el poder de producir y reproducir diferencias entre territorios conforme a sus diversas capacidades ecológicas y sus distintos modelos de acumulación, alterando y complejizando las conexiones entre países centrales y periféricos (SCRIBANO, 2008). EI mal llamado 'comercio' de agua virtual es más bien una transferencia, porque el país que la originó no obtiene ganancia o compensación económica alguna, al ser económicamente invisible y políticamente silencioso (ALLAN, 2003), se convierte en un velado, sutil y deliberado mecanismo de acumulación por desposesión, existiendo cierto empeño, en el contexto del orden global, por fomentar la especialización hidrológica de los países del Sur en la división internacional del trabajo.

Conforme el comercio internacional aumenta, los flujos de agua virtual hacen lo propio, pasando (en valores absolutos) de los $450 \mathrm{~km}^{3}$ calculados en 1961 a los 1.340 $\mathrm{km}^{3}$ verificados en 2000 (FAO, 2003). Según Chapagain y Hoekstra (2004), el comercio agrícola absorbe el mayor caudal de ese movimiento (61\%), seguido por los productos industriales $(22 \%)$ y la ganadería (17\%), aunque estimaciones más recientes asignan un $67 \%$ a la agricultura, un $23 \%$ a la ganadería y un $10 \%$ a la industria (GRAJALES QUINTERO; JARAMILLO ROBLEDO; CRUZ CERÓN, 2008). Chapagain y Hoekstra (2004) estiman que los principales 356 bienes habitualmente transados en el mercado mundial representan desplazar $1.263 \mathrm{~km}^{3}$ de agua.
Evidentemente, el 'comercio' del agua virtual genera un importante ahorro del recurso en los países importadores, acarreando su posible deterioro y sobreexplotación en las naciones exportadoras: se observa con cada vez mayor asiduidad que países con insuficiente dotación natural de agua asumen estrategias de acumulación basadas en políticas de 'ahorro' o 'ajuste', abandonando parcial o totalmente la producción de bienes hidro-intensivos, comprándoselos a otros países y dedicando el agua así 'liberada' a otros fines (ALLAN, 2003; ZIMMER; RENAULT, 2003; LLAMAS MADURGA, 2005). Es por eso que, para un autor como Pengue (2006, p. 62), el comercio agrícola mundial representa una gigantesca transferencia de agua bajo la forma de commodities desde regiones donde abunda a bajo costo hacia otras donde escasea, es cara y su uso compite con otras prioridades.

El continente asiático y, sobre todo, China e India, constituyen el principal destino de los flujos de agua virtual; para sostener su vertiginoso crecimiento económico, devoran las materias primas agroalimentarias y los minerales de América Latina y El Caribe. Según Chapagain y Hoekstra (2003) y Zimmer y Renault (2003), los principales países importadores de agua virtual son Sri Lanka, Japón, Holanda, Corea del Sur, China, Indonesia, España, Egipto, Alemania, Italia, el Reino Unido, México, Hong Kong, Irán y Arabia Saudita; por su parte, las naciones que más recursos hídricos transfieren al exterior son Estados Unidos, Canadá, Tailandia, Argentina, Brasil, Costa de Marfil, India, Australia, Vietnam, Ghana, Ucrania, Francia y Guatemala. La complejidad del fenómeno obliga a interpretar con cautela los datos agregados según países; desde el punto de vista geopolítico, la transferencia de recursos hídricos bajo la forma de mercancías impide identificar realmente quién o quiénes usan el agua y con qué objetivo lo hacen (MACHADO ARAOZ, 2010). Los principales usuarios del recurso en un país exportador de agua virtual pueden ser empresas o corporaciones transnacionales cuyas filiales y subsidiarias, al hallarse diseminadas por el mundo, controlan esos flujos a escala global, ora redirigiéndolos hacia sus propias naciones de origen para aliviar el déficit hídrico de aquellas o compensar la pérdida del recurso que implican las exportaciones, o bien remesándolos hacia los países donde se hallan sus principales nichos de comercialización y/o se desarrolla parte de 
v.17, n. 2, p. 6-28, jul./dez. 2015

sus procesos productivos. Lo anterior nos obliga a preguntarnos quién acapara y controla los recursos hídricos de un país y, en contrapartida, quién es excluido de su acceso y gestión (COLLADO; SAAVEDRA, 2010; BELTRÁN; VELÁZQUEZ, 2014).

Sorprendentemente, la Argentina se ubica entre las primeras naciones exportadoras netas de agua virtual. Investigadores como Chapagain y Hoekstra (2003) y Zimmer y Renault (2003) han estimado ese flujo en el orden de los 52.000 y los 66.000 millones de metros cúbicos, respectivamente. En cualquier caso, ambos estudios ubican a la Argentina en el cuarto lugar a nivel mundial, luego de Australia, Estados Unidos y Canadá (PENGUE, 2006). Sin embargo, análisis más recientes, como los de Rodríguez-Iturbe, señalan que cada año la Argentina remesa al exterior 119.000 millones de metros cúbicos, situándose así en el segundo escalafón, detrás de los Estados Unidos (VIANO, 2013). No obstante, esos guarismos deben interpretarse con cierta reserva, toda vez que no discriminan situaciones regionales, provinciales 0 locales; aún tratándose de un país dotado, en términos relativos, de una vasta disponibilidad hídrica, eso no impide que el $70 \%$ del territorio argentino presente características de aridez y semi-aridez, dato que no permite descartar la posibilidad de que el recurso haya sido expoliado de áreas en las que escasea. Se atribuye al boom de la soja, desatado a partir de 1996 y aún hoy día vigente, con China como principal destino comercial $(65 \%)$, la responsabilidad por la sustancial participación argentina en ese drenaje de recursos hídricos, siendo el caso más exhaustivamente estudiado: Pengue (2006) estima que, durante la campaña agrícola 2004/2005, ese cultivo implicó la sangría al exterior de 42.500 millones de metros cúbicos $\left(\mathrm{m}^{3}\right)$, en tanto que Merenson (2011) sitúa esas 'exportaciones' en el orden de los 55.000 millones de metros cúbicos para la campaña 2007/2008. La huella hídrica de la minería metalífera argentina no ha sido estimada en términos generales.

\section{La minería metalífera en la Argentina (1993-2014): breve aproximación general}

Oriundo de los centros de poder del capitalismo, el neoliberalismo forjó en la década de 1990 un período de esplendor para el extractivismo en América Latina en general y la Argentina en particular, fase que sería paradójicamente perpetuada por el posterior advenimiento y consolidación, ya en pleno Siglo XIX, de gobiernos autoproclamados 'progresistas' y 'postneoliberales' (SEOANE, 2012), críticos respecto del 'capitalismo salvaje' imperante durante el decenio anterior. Solidaridades tejidas entre el comercio internacional, la lógica rentística-financiera y la explotación extranjerizada de la naturaleza diseñaron un esquema propicio para el desarrollo del núcleo duro del extractivismo argentino: la mega-minería del oro, la plata y el cobre, el agro-negocio basado en la soja transgénica y los hidrocarburos (FRECHERO, 2013).

En América Latina, la antigua relación entre minería metalífera y acumulación por desposesión ha sido renovada y perfeccionada. En la época colonial, la explotación de las minas americanas y el comercio (y contrabando) de oro y plata con destino a Europa fueron el motor de la acumulación primitiva que hizo posible la primera Revolución Industrial (MANDEL, 1969). Solidaridades tejidas entre diversos factores -agotamiento de reservas, baja ley de los minerales remanentes, cierre de yacimientos por graves episodios de contaminación, aumento de la rigurosidad de las legislaciones ambientales que regulan la minería en Estados Unidos, Canadá, Australia e Inglaterra, existencia de ingentes riquezas sin explotar en países periféricos donde persisten laxos controles laborales y ambientales, etc.- han coadyuvado a que, sigilosamente, el centro de gravedad a escala mundial de la minería metalífera se haya desplazado en la actualidad hacia la periferia. Oro, plata, cobre y litio forman parte de la matriz y espina dorsal del sistema capitalista globalizado: el oro sirve de respaldo al capital acumulado en los bancos centrales y los organismos financieros internacionales -que absorben entre el 12 y el $22 \%$ de la producción-, y es marginalmente utilizado en chips, circuitos impresos, nano-tecnologías, aplicaciones industriales, medicinales y de tecnología espacial (3\%); junto a la plata, el oro también satisface el consumo suntuario de joyas y alhajas, que representa el $75-85 \%$ de toda la extracción aurífera mundial. El cobre resulta imprescindible para la industria de la construcción y el sistema energético, y el litio es estratégico para la industria química y electrónica, del aluminio, el vidrio, la cerámica y los esmaltes, automóviles eléctricos y pilas/baterías recargables para teléfonos celulares y computadoras 
(ODRIOZOLA, 2003; SCHIAFFINI, 2004; CACACE, GÓMEZ; MORINA, 2012). En ese contexto, setenta países han tomado créditos del Banco Mundial durante los últimos veinte años con el propósito de modificar sus legislaciones mineras y así atraer a inversores extranjeros.

El Estado argentino diseñó un andamiaje legal extremadamente favorable para el sector: estabilidad fiscal por 30 años; desgravación total de las importaciones; reembolso del Impuesto al Valor Agregado (IVA); doble deducción de los costos de exploración; regalías provinciales irrisorias $3 \%$ (como máximo) del valor bruto en boca de mina-; eliminación de gravámenes y tasas municipales; exención del impuesto al cheque, a los sellos, a los combustibles y a la ganancia mínima presunta; permiso para exportar y remitir utilidades al exterior sin pagar impuestos; $y$, posteriormente, exención del IVA (SCHIAFFINI, 2004; GÓMEZ LENDE, 2005; SVAMPA; BOTTARO; SOLÁ ÁLVAREZ, 2009; CACACE; GÓMEZ; MORINA, 2013). A esas condiciones se añadió luego la posibilidad, para las mineras extranjeras, de establecer cuentas off shore como base para sus activos financieros y como plazas de depósito de las divisas generadas por sus exportaciones (MACHADO ARAOZ et al., 2011). El Tratado de Integración Minera con Chile, asimismo, convirtió a la Cordillera de Los Andes en una suerte de 'tercer país' gobernado por las mineras transnacionales. Lo anterior coadyuvó a desencadenar un vertiginoso boom minero: 4.000 millones de dólares fueron destinados al sector entre 1995 y 2005; el número de empresas se incrementó veinte veces, y las perforaciones hicieron lo propio en un $800 \%$ (GÓMEZ LENDE, 2005). Sólo en un quinquenio (20032007), las inversiones se octuplicaron, pasando de U\$S 660 millones a U\$S 5.600 millones; la tasa de crecimiento del producto minero se duplicó respecto de la tasa promedio de aumento del PBI; y el crecimiento acumulado de proyectos mineros fue, entre 2003 y 2011 , superior al $3.300 \%$ (ARGENTINA, 2008; SVAMPA; BOTTARO; SOLÁ ÁLVAREZ, 2009; CACACE; GÓMEZ; MORINA, 2013).

Si bien en la Argentina el número de proyectos mineros es apabullante, los casos más paradigmáticos son los de la provincias de Catamarca -donde se emplazan la mina de cobre, oro y plata Bajo La Alumbrera (controlada por la suiza Glencore-Xtrata Copper y las canadienses Yamana Gold y
Goldcorp) y el depósito de litio Salar del Hombre Muerto (en manos de la estadounidense FMC Lithium)-, San Juan donde se localiza la mina aurífera, argentífera y cuprífera Veladero (de la canadiense Barrick Gold y la estadounidense Homestake Mining ${ }^{3}$ ), el yacimiento de oro Gualcamayo (de Yamana Gold) y el depósito de oro y plata Casposo (de la australiana Troy Resources)- y Santa Cruz -donde se sitúan las minas de oro y plata Cerro Vanguardia (de la anglo-sudafricana Anglogold-Ashanti y la petrolera brasileña Petrobras), Manantial Espejo (de la canadiense Pan American Silver y la estadounidense Silver Standard Resources) y San José-Huevos Verdes (del magnate anglo-peruano Hochschild y la canadiense McEwen Mining), el yacimiento de plata Martha (de la canadiense Coeur, recientemente abandonado en 2010) y el depósito aurífero Cerro Negro (de Goldcorp)(Cuadro 1). En todos los casos, los minerales extraídos se destinan a la exportación.

Otrora distinguido en el marco de la división internacional del trabajo como el 'granero del mundo', la Argentina se ha convertido -pese a casi no contar con antecedentes históricos en el desarrollo de la actividad- en la 'niña mimada de la minería', epíteto con el que se lo conoce en los foros internacionales del sector (BERARDI, 2010). En la Argentina, la tasa de retorno de la inversión minera es una de las más altas del mundo $(16 \%)$, y las respectivas tasas de rentabilidad de los principales yacimientos en actividad oscilaron durante el período 19982011 , según el caso, entre el 54 y el $102 \%$, esto es, entre cinco y diez veces más que el porcentaje de utilidades obtenido por las mismas empresas en sus minas de América del Norte (GÓMEZ LENDE; VELÁZQUEZ, 2004; GÓMEZ LENDE, 2005; BASUALDO; MANZANELLI, 2011; CACACE; GÓMEZ; MORINA, 2013). Estas fabulosas ganancias se deben no sólo a las riquezas de los yacimientos y las ventajosas condiciones jurídicas de operación ya comentadas, sino también gracias a la externalización al Estado de los costos de producción privados: el aparato burocrático asegura el mejoramiento de caminos y puentes, cede tierras fiscales para la construcción de puertos y aeropuertos privados, realiza obras de adaptación de la red hídrica y vial, y garantiza un ilimitado abastecimiento de

\footnotetext{
3 En 2001, Barrick Gold y Homestake Mining se fusionaron, siendo esta última absorbida por la primera.
} 


\section{REA - Revista de estudos ambientais (Online) \\ v.17, n. 2, p. 6-28, jul./dez. 2015}

energía a través de costosas obras de tendido de líneas eléctricas de alta tensión (500 kV). Es la 'corporatización' del territorio de la que habla Santos (1996a), un orden de prioridades y una producción limitada de racionalidad que benefician sólo a los agentes hegemónicos.

Obstando las inversiones que demanda la modernización y adecuación de la configuración territorial regional a los intereses mineros, el Estado nacional otorga subsidios y reintegros comerciales y fiscales que anulan e incluso revierten los costos laborales y tributarios de las empresas, a la vez que permite a éstas descontar del pago de regalías provinciales los costos de trituración, molienda, fundición, refinación, transporte, seguros y comercialización. Queda claro que la funcionalidad jurídicoeconómica del aparato burocrático al saqueo extractivo como forma de acumulación por desposesión raya en el más irracional de los servilismos cuando se advierte que la actividad da cuenta de sólo el $3 \%$ de las exportaciones argentinas, el $0,06 \%$ del empleo y el $0,4 \%$ de la recaudación fiscal (MACHADO ARAOZ et al., 2011; CACACE; GÓMEZ; MORINA, 2013).

\section{Cuadro 1 - A) Minería metalífera. Principales yacimientos metalíferos en la República Argentina. Año}

2014, B) República Argentina, según división político-territorial (provincias).

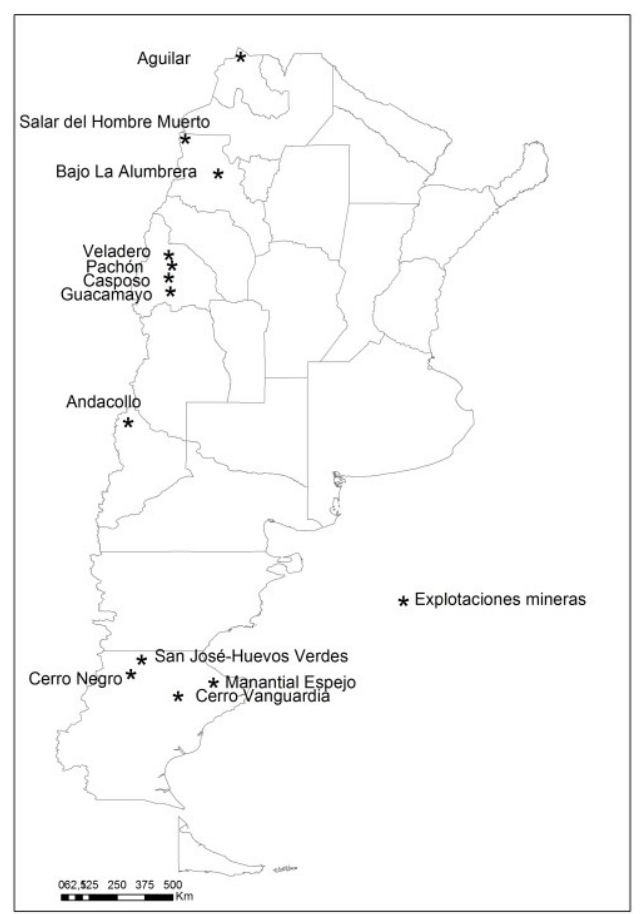

A)

Fuente: Elaboración propia (2015).

Sin embargo, el orden global y las verticalidades impuestas por las empresas transnacionales mineras son ampliamente resistidos por las comunidades locales. En efecto, si algo distingue a la mega-minería metalífera en América Latina, es el elevado nivel de conflictividad socio-ambiental y política que ésta genera; así lo demuestran las estadísticas del Observatorio Latinoamericano de Conflictos Mineros, que revelan la existencia, en el sub-continente, de 206 conflictos relacionados con la actividad; Perú (36), Chile (35) y México (34) encabezan ese listado, seguidos por la Argentina (26), Brasil (20) y Colombia (12)

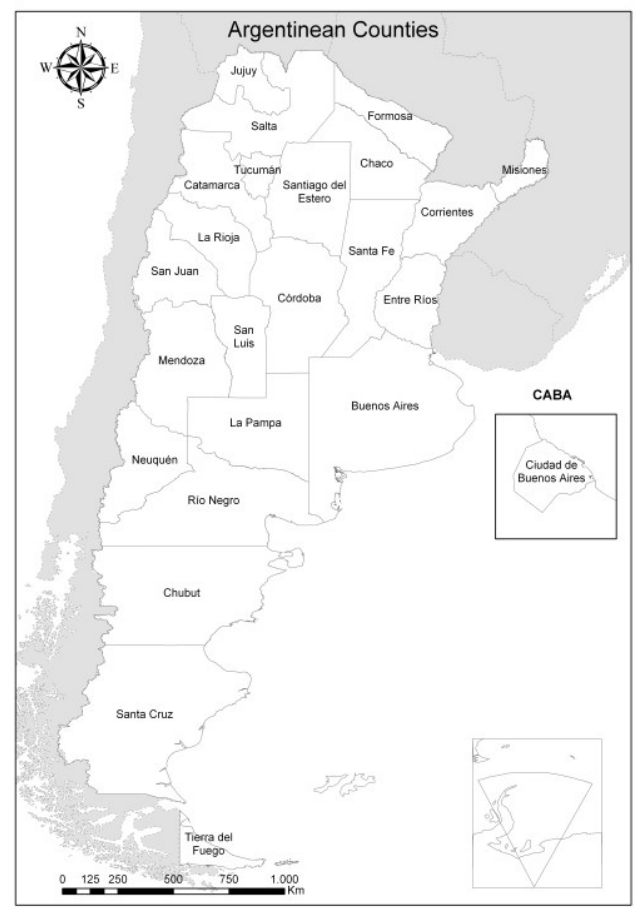

B)

(OCMAL, 2014), registrándose también episodios no menos significativos en países como Guatemala, El Salvador, Honduras, Costa Rica, Panamá y Ecuador, entre otros. Si bien entre los principales fundamentos y detonantes de la resistencia a la minería en la Argentina se hallan cuestiones económicas -empobrecimiento de comunidades, funcionamiento de economías de enclave sin nexos con la sociedad local, crisis de campesinos y aborígenes-, territoriales -privatización de tierras y caminos, expropiaciones-, laborales -bajo nivel de generación de empleo, gran proporción de fuerza trabajo extrarregional y 
extranjera, condiciones precarias, extremas y/o ilegales de explotación- y socio-políticas control de medios de comunicación, censura en instituciones educativas, asistencialismo y otras prácticas espurias orientadas a conquistar el favor popular o 'licencia social', represión de la protesta, militarización-, el motor de la rebelión es básicamente ambiental -destrucción de recursos paisajísticos, contaminación a gran escala por drenajes ácidos de roca, derrames tóxicos, rotura de mineraloductos, filtraciones de piletas de concentrado/lixiviación y colapsos de escombreras y diques de cola, aparición de enfermedades y graves patologías-. En ese marco, la problemática hídrica ocupa un lugar destacado, debido a la escasez y contaminación del agua que ocasiona la actividad.

5 Minería metalífera, acumulación por desposesión y problemática hídrica. La huella hídrica de la actividad: de la depredación y contaminación del recurso a la sangría de 'agua virtual'

Como resultado del descenso, a escala mundial, de la ley de los metales más valiosos, y del afán de las empresas de reducir sus costos y aumentar sus ganancias, la minería metalífera actual no es la de antaño; las típicas explotaciones en galerías subterráneas han sido mayoritariamente reemplazadas por sistemas de producción más eficientes: se trata de la apertura de mega-yacimientos a cielo abierto (open pit), sustentada en el uso intensivo de explosivos, energía eléctrica y agua. Ese cambio ha dado lugar a un moderno (y más agresivo) modelo de extracción, que implica demoler literalmente montañas y cerros, remover, triturar y moler extraordinarias cantidades de roca y depositar ese material en enormes piletas de concentrado donde -con el llamado 'método Merril-Crowe'- los metales son lixiviados mediante una amalgama química en la que intervienen millones de litros de agua, mezclados con cianuro de sodio, ácido sulfúrico o mercurio, a su vez combinados con compuestos como sales de plomo y zinc, azufre, antimonio, cal, mineral hierro y arsénico (GÓMEZ LENDE; VELÁZQUEZ, 2008; MACHADO ARAOZ et al., 2011). Éste es el sistema de producción utilizado en casi todas las minas metalíferas de la Argentina, a excepción de la extracción de litio en Salar del Hombre Muerto.
La adopción de ese sistema de explotación a 'cielo abierto' implica que la actividad opere como un mecanismo de "expropiación ecológica" (MACHADO ARAOZ, 2009a), transfiriendo a los países importadores de recursos minerales el agua, la energía y la capacidad de sumidero de las áreas donde se emplazan los yacimientos. En ese esquema o patrón de acumulación, la cuestión hídrica reviste una doble función: la de insumo imprescindible, estratégico e irreemplazable para la producción; y la de destino del vertido (deliberado o no) de sustancias contaminantes que afectan severamente la calidad del recurso u ocasionan su pérdida. El segundo caso -el uso del agua como sumidero para los desechos de la actividad- se observa en la pulverización de montañas y cerros en la Cordillera de Los Andes -liberando el arsénico, el mercurio, el plomo, otros metales pesados y minerales radiactivos (uranio) contenidos en la roca, permitiéndoles acumularse en ríos y acuíferos y así generando drenajes ácidos que promueven la disolución de sustancias tóxicas en el agua-; en la degradación/contaminación de los cursos y cuerpos de agua superficiales (ríos $^{4}$ arroyos, abrevaderos, lagunas, humedales), los reservorios subterráneos e incluso el agua potable con grasas, aceites, cobre, cromo, cianuro, sulfatos, vanadio, plomo, arsénico, aluminio, mercurio y otros metales disueltos, a raíz de las roturas de los mineraloductos, las fallas de las piletas de concentrado y lixiviación, y los derrames ocurridos dentro de los yacimientos; y en los drenajes ácidos provocados por diques de colas y escombreras de material estéril, donde se almacenan millones de toneladas de roca cianurada cuyo letal contenido será lentamente absorbido durante miles de años por vertientes y napas, con nefastas consecuencias para la biodiversidad, los ecosistemas, los agricultores y campesinos y la salud de la población en general.

Como el uso intensivo del recurso hídrico resulta clave y vital para la minería a cielo abierto, las empresas suelen emplear inescrupulosamente cualquier método que les permita apropiarse monopólicamente de los ingentes volúmenes de agua requeridos para la lixiviación, hidratado y concentrado de los minerales: desviar las nacientes y vertientes de arroyos y ríos para formar lagunas, expoliar los acuíferos subterráneos

\footnotetext{
${ }^{4}$ Sólo las seis roturas del mineraloducto de Bajo La Alumbrera contaminaron más de 200 km de ríos.
} 
y apoderarse de grandes reservas de aguas fósiles son algunas de las prácticas predatorias más habituales, a las cuales se añaden la destrucción de los glaciares trasandinos y de numerosos permafrost (glaciares de roca) $^{5}$. El uso intensivo del agua es transversal a todas las etapas del proceso productivo de la mega-minería metalífera a cielo abierto: en la fase de extracción, es requerida para abastecer al campamento minero y para regar los caminos y el área de voladuras, para de ese modo reducir el polvo en suspensión; durante el procesamiento y concentración del mineral extraído, para separar los metales buscados del material estéril, ora por flotación, ora vía lixiviación por pilas; y para el transporte -en algunos casos el concentrado circula a través de mineraloductos que funcionan impulsados por agua a presión- (MACHADO ARAOZ, 2010). Como resultado, esta minería representa una grave amenaza para una de las últimas grandes reservas de agua dulce del planeta en general y de América Latina en particular: los glaciares cordilleranos andinos.

En la Argentina, las empresas mineras han entablado una despiadada e inhumana competencia respecto de otros usos del territorio en relación a la disponibilidad y utilización del agua, especialmente en las zonas áridas y semiáridas $^{6}$, donde se desarrolla una velada pero sistemática privatización del recurso otra forma de verticalización y corporatización del territorio- en beneficio de las firmas transnacionales y en perjuicio de las comunidades locales. El ingente consumo hídrico de la actividad, las prácticas predatorias de las empresas y el continuo e ininterrumpido funcionamiento de las minas durante las 24 horas del día determina que se verifique una aguda escasez de agua en numerosos poblados cordilleranos, incluso en épocas de nevada o deshielo, cuando teóricamente debería abundar. En provincias como San Juan y Catamarca, esa suerte de sequía 'inducida' afecta desde hace ya casi una década a las comunidades cercanas a los yacimientos explotados, acarreando consigo la ruina para la agricultura bajo riego y las economías campesinas, amén de la

5 En San Juan, numerosos glaciares de roca (permafrost) activos e inactivos han sido destruidos por mineras para desviar, en función de los intereses de éstas, las vertientes de los ríos Jáchal y Desaguadero. ${ }^{6}$ El promedio pluviométrico anual oscila entre $400 \mathrm{~mm}$ (Catamarca) y $100 \mathrm{~mm}$ (San Juan). pérdida de cultivos y animales, y la preocupante escasez de agua para consumo humano (GÓMEZ LENDE; VELÁZQUEZ, 2008)

No es tarea fácil determinar los flujos de agua virtual asociados a la minería metalífera; por el contrario, ello supone un trabajo arduo, plagado de escollos metodológicos. Si bien para cumplimentar tal propósito sólo se requieren los datos correspondientes a apenas dos indicadores empíricos concretos -volumen de extracción de minerales y nivel de consumo de agua en los yacimientos-, la información dista de ser fácilmente accesible. La miríada de dificultades que esto implica se desagrega en tres grandes grupos: por un lado, los problemas relativos al conocimiento de las cifras reales de producción de los yacimientos que actualmente se encuentran bajo explotación; por otro lado, la escasez de datos consistentes respecto del consumo hídrico de las minas; y finalmente, los inconvenientes técnicos para estandarizar $u$ homogeneizar los cálculos de los flujos de agua virtual, en parte determinados por las diversas características geológicas de los yacimientos y las especificidades intrínsecas a los respectivos procesos productivos, y en parte también derivados del hecho que los estudios sobre agua virtual que operan como modelos metodológicos a nivel internacional tampoco abundan en precisiones respecto de esta problemática.

Aunque parezca inverosímil, un dato tan básico como el volumen de minerales metalíferos extraídos en la Argentina sólo es conocido a ciencia cierta por las propias empresas, siendo prácticamente un misterio para el resto de la sociedad, incluso para el propio Estado. Si bien los organismos burocráticos vinculados al sector, como la Secretaría de Minería de la Nación, hacen gala de informes cada vez más ostentosos y presuntuosos sobre el acelerado crecimiento del sector, las millonarias inversiones, las abultadas exportaciones y las optimistas proyecciones estimadas respecto de la evolución del empleo (ARGENTINA, 2012), llamativamente nada dicen acerca de las estadísticas de producción. Nunca han existido, de hecho, datos oficiales actualizados a nivel nacional desagregados según yacimientos: luego del Censo Nacional Minero 2003-2004 (ZOLEZZI; MIRÓ; MUNIZAGA, 2005), la Secretaría de Minería informó sobre el particular hasta 2009, proporcionando datos parciales sobre cuya base el Instituto Nacional de Estadística 
y Censos diseñó y elaboró estadísticas desagregadas por provincias y según minerales extraídos, pero sin discriminar entre yacimientos $\mathrm{o}$ proyectos (INDEC, 2010). Omitiendo dar cuenta del volumen de las exportaciones (y menos aún de la producción total), la Secretaría de Minería se limita desde entonces a publicar información sobre el valor del comercio internacional minero de la Argentina (ARGENTINA, 2010). No existiendo información oficial confiable a nivel nacional, sólo es posible dar cuenta, fuera de ese ámbito, de los relevamientos fragmentados, particulares y de variable nivel de detalle realizados por las Direcciones de Minería de determinadas provincias; y aún en los casos puntuales en que esa tarea ha sido realizada, no existe uniformidad en la forma de presentar la información -algunas jurisdicciones presentan datos globales, en tanto que otras discriminan según yacimientos-, observándose asimismo groseras discrepancias e inconsistencias respecto de la Secretaría de Minería de la Nación en lo que atañe a los yacimientos que efectivamente se encuentran en etapa de explotación (LINARES, 2011) ${ }^{7}$.

Como resultado, esa información esencial sólo puede ser recabada de manera aislada recurriendo a los datos declarados por las propias empresas. Los volúmenes de minerales extraídos a menudo son consignados en sus páginas web corporativas, o bien divulgados por portales de Internet vinculados al sector, como Mining Press, InfoMine, El Pregón Minero y la Cámara Argentina de Empresarios Mineros (CAEM). Obstando que se trata de la única información disponible, no es menos cierto que ésta puede hallarse oscurecida o distorsionada por importantes niveles de subregistro vinculados a una típica estrategia de acumulación de las mineras transnacionales: el contrabando o la exportación clandestina. Con frecuencia, los volúmenes de producción de los metales por los cuales las empresas deben tributar al fisco son subdeclarados, adulterados o falseados para así eludir el pago de las regalías provinciales; las compañías a menudo también omiten informar la comercialización de aquellos minerales que se hallan exentos de cargas

\footnotetext{
${ }^{7}$ El Ente de Fomento a la Minería de la Provincia de Santa Cruz (Fomicruz), por ejemplo, no consignó a los yacimientos San José-Huevos Verdes y Manantial Espejo, pero la existencia (y funcionamiento) de éstos sí es reconocida por la Secretaría de Minería de la Nación; a su vez, en su último informe (2009) ese organismo no registró a Cerro Vanguardia (que opera desde 1998), pero Fomicruz sí lo hizo (LINARES, 2011).
}

fiscales. Así pues, las cifras declaradas por las empresas mineras rara vez son fieles a la verdad, pudiendo expresar, en algunos casos, abismales diferencias respecto de los guarismos reales ${ }^{8}$.

Si acceder al conocimiento de datos fehacientes relativos a la producción minera en la Argentina resulta tan dificultoso y desconcertante, ¿qué puede decirse entonces de los niveles de consumo hídrico de los yacimientos? Al ser objeto de agudas polémicas, existen grandes variaciones en las estimaciones, dependiendo de quién es el actor que las efectúa; en gran medida, los datos disponibles provienen casi unilateralmente de las propias empresas $\mathrm{y} / \mathrm{o}$ consultoras del sector, con obvios intereses en la materia (MACHADO ARAOZ, 2010). La absoluta ausencia de caudalímetros en las adyacencias de los pozos que abastecen de agua subterránea a todas las minas metalíferas argentinas ${ }^{9}$, el desvío de vertientes, la destrucción de glaciares y la imposibilidad de efectuar controles estatales efectivos debido a las inhóspitas condiciones cordilleranas $^{10}$, la privatización y militarización de las áreas que rodean a los yacimientos ${ }^{11}$ y la mimetización de los actores políticos con los intereses de las mineras transnacionales, vedan el fluido acceso a los datos del consumo hídrico de la actividad. Quedan disponibles sólo tres alternativas: los permisos de uso del recurso otorgados por gobiernos provinciales, los guarismos declarados por las mineras (avalados por el Estado) y las estimaciones independientes de organizaciones ambientalistas y estudios académicos (críticas de las cifras oficiales).

\footnotetext{
${ }^{8}$ En Catamarca, las roturas del mineraloducto de Bajo La Alumbrera revelaron que la carga de concentrado contenía -amén del oro, el cobre y el molibdeno por los cuales las empresas tributan regalías a la provincianumerosos minerales de gran valor (metalíferos, radiactivos y raros), exportados clandestinamente para abastecer a industrias extranjeras de punta que fabrican superconductores y nuevas aleaciones. Como resultado, se estima que Xtrata Copper, Yamana Gold y Goldcorp evadieron al fisco más de 40.000 millones de dólares (NALM, 2014a). Barrick Gold en Veladero sólo paga regalías por el oro, pero no por el cobre, el hierro y el mercurio. $Y$ en Cerro Vanguardia, Anglogold-Ashanti habría consignado en 2010 valores y volúmenes de extracción de oro un $640 \%$ y $820 \%$ por debajo de los reales (LINARES, 2011).

${ }_{9}^{9}$ Según Linares (2011), la Argentina es el único país del mundo sin caudalímetros en los pozos mineros.

${ }_{10}$ Veladero, por ejemplo, funciona en las cumbres cordilleranas a más de 5.000 metros sobre el nivel del mar.

${ }^{11}$ Barrick Gold se apropió del único camino de $150 \mathrm{~km}$ que une a San Juan con Chile.
} 
Otro problema atañe a los atributos propios de cada yacimiento y explotación, que tornan dificultosa la estandarización del cálculo de los flujos de agua virtual asociados a la extracción minera: la diversidad de la geología de los yacimientos (estratigrafía, diseminación de los minerales), su diferente composición mineralógica, los distintos niveles de ley de los metales extraídos -recuérdese que, a menor ley, mayor volumen de agua requerido- y la utilización o no de mineraloductos para el transporte del concentrado -que implican un consumo adicional- son factores que influyen en las estimaciones. La ausencia casi absoluta de estudios a nivel internacional que brinden parámetros y criterios respecto de la relación entre agua virtual y minería metalífera también supone otro escollo. Sólo es posible utilizar como referencia dos estimaciones extremadamente disímiles entre sí: la de la FAO (2003), que señala que la producción de cada gramo de oro exige 230 litros de agua; y la de Garibay Orozco (2010), que afirma que actualmente se requieren 186.600 litros de agua para obtener 20 gramos de oro -es decir, 9.330 litros por gramo-. En ambos casos, nada se dice con respecto a los requerimientos hídricos de la extracción de otros metales. Esto torna aún más compleja la realización de cálculos exactos, debido a que la inmensa mayoría de las minas argentinas en explotación son poli-metálicas. En el caso de la Argentina, la revisión bibliográfica desarrollada sólo arrojó como resultado los cálculos de Machado Araoz (2009b) -quien estimó la huella hídrica de Bajo La Alumbrera en 203.000 litros por tonelada de cobre-; y la Revista Oro del Sur (publicación de la minera Cerro Vanguardia y, por esa razón, sujeta a los mismos problemas de confiabilidad anteriormente citados), que sostiene que en la Argentina cada onza (31,1 gramos) de oro insume, en promedio, 557 litros de agua (MINING CLUB, 2013) -esto es, 18 litros por gramo-.

Si bien se ha conseguido recabar datos referidos al volumen de producción de todas las minas, la información obtenida en relación al consumo de agua es parcial, contándose con datos empíricos para Bajo La Alumbrera y Salar del Hombre Muerto (Catamarca), Cerro Vanguardia, Manantial Espejo y Cerro Negro (Santa Cruz), Veladero, Gualcamayo y Casposo (San Juan), pero no para las minas santacruceñas
San José-Huevos Verdes y Martha ${ }^{12}$. En todos los casos se han verificado severas discrepancias entre las diferentes fuentes consultadas, como se detalla a continuación.

Si bien las empresas concesionarias de Bajo La Alumbrera cuentan con un permiso provincial de extracción situado en el orden de los 1.100 litros por segundo, reconocen consumir sólo $254 \mathrm{~L} / \mathrm{s}$; sin embargo, sus primeros informes de impacto ambiental señalan requerimientos hídricos de $900 \mathrm{~L} / \mathrm{s}$, en tanto que organizaciones ambientalistas (NALM, 2013a) y académicos (MACHADO ARAOZ, 2009b) aseveran que el volumen de agua extraído es equivalente al permitido por la provincia de Catamarca $(1.100 \mathrm{~L} / \mathrm{s})$. El ingente consumo hídrico de Bajo La Alumbrera obedece a la baja ley mineralógica del yacimiento $(0,76 \%$ para el cobre, $1,1 \mathrm{~g} / \mathrm{t}$ para el oro), y también al transporte del concentrado vía un mineraloducto de $216 \mathrm{~km}$ de longitud. En el caso del también catamarqueño yacimiento Salar del Hombre Muerto, sólo se cuenta con las aseveraciones de la propia firma, que afirma utilizar 304.000 litros de agua diarios (NALM, 2012a), es decir, 84,44 L/s. Cerro Vanguardia goza de un permiso provincial de extracción de 100.000.000 litros mensuales $(38,6 \mathrm{~L} / \mathrm{s})$, de los cuales esa empresa reconoce consumir 65.000 litros/mes $(25,1$ L/s) (GARCÍA DE LAS TONGAS, 2009). Otros estudios, sustentados en un informe hidro-geológico de la propia minera en 2008 , afirman que ésta absorbe entre 90.000 .000 y 110.000 .000 litros de agua mensuales, esto es, un promedio de 36.000 .000 litros diarios (OPI SANTA CRUZ, 2011) y 41,7 L/s. Esos niveles de consumo explicarían la desaparición (secado) de un río y de numerosos arroyos en el área de influencia de la mina, y el hecho de que las localidades santacruceñas situadas en un radio de 154 $\mathrm{km}$ respecto de Cerro Vanguardia (Puerto San Julián) sufran graves problemas de abastecimiento de agua potable. La demanda hídrica de Manantial Espejo se estima en el orden de los $100 \mathrm{~L} / \mathrm{s}$ (OCMAL, 2015), en tanto que el informe de impacto ambiental de Cerro Negro preveía el consumo de 12,9 litros de agua por segundo (OROPLATA S.A., 2010). Si bien para este último caso, al ser tan reciente -la explotación comenzó recién en 2014-, no es posible contar con cálculos alternativos que

\footnotetext{
${ }^{12}$ Martha se encuentra inactiva desde 2010 , y su último informe hidro-geológico data de 2001, antes del inicio de la explotación (OPI SANTA CRUZ, 2011). No se obtuvieron datos para San José-Huevos Verdes.
} 
refuten esos datos, aquí se considera que una demanda hídrica tan baja resultaría inviable para operar una mina de esa índole.

Otro caso aún más controvertido objeto de aguda polémica- es el de San Juan. Las minas Veladero, Gualcamayo y Casposo cuentan con permisos provinciales de extracción situados en el orden de los $110,116,65$ y 12,5 litros por segundo, respectivamente; de esos umbrales máximos, el Departamento de Hidráulica de San Juan asevera que, durante el primer semestre de 2011, Veladero consumió en promedio unos 63 L/s, Gualcamayo sólo 35 /s y Casposo apenas $5 \mathrm{~L} / \mathrm{s}$; en conjunto, esto representaría el $0,96 \%$ del consumo hídrico de toda la provincia (SAN JUAN, 2013a). Ahora bien, esos datos no reflejan en modo alguno la realidad, ni son congruentes respecto de la grave problemática hídrica que, 'casualmente' desde el inicio de la mega-minería metalífera, atraviesa gran parte del territorio provincial. Las localidades andinas sufren cortes programados en el suministro de agua para riego y consumo animal de hasta siete días de duración (GÓMEZ LENDE; VELÁZQUEZ, 2008), y millares de personas se desplazan diariamente, recorriendo largas distancias para abastecerse del vital elemento (SVAMPA; BOTTARO; SOLÁ ÁLVAREZ, 2009). Se estima que, en la campaña agrícola 2011/12, el caudal de agua para riego mermó casi un 30\% (NALM, 2012b). El gobierno sanjuanino declaró en Emergencia Hídrica a toda la provincia, duplicando a los agricultores el precio del canon que deben abonar al Departamento de Hidráulica, y llegando al extremo de colocar 8.000 medidores, no a las empresas mineras, sino a los pobladores rurales y sectores urbanos residenciales, para evitar el 'derroche' (NALM, 2013b).

Obstando lo anterior, es difícil sostener que Veladero consuma apenas 63 $\mathrm{L} / \mathrm{s}$, existiendo varias evidencias de lo contrario. En la vecina provincia de Mendoza, el proyecto minero San Jorge -de envergadura mucho menor a la de la mina sanjuanina- prevé requerir $141 \mathrm{~L} / \mathrm{s}$ (MACHADO ARAOZ et al., 2011). Estimaciones independientes basadas en bibliografía académica especializada y en el Manual del Sistema de Estimación de Costos y Capital para la Minería que la Oficina de Minas del Departamento del Interior del Gobierno de los Estados Unidos diseñó a partir de datos obtenidos de compañías mineras norteamericanas, arrojan como resultado que un proyecto de esa magnitud implicaría disponer de un metro cúbico $(1.000$ L) por segundo (RODRÍGUEZ PARDO, 2009). Incluso debates parlamentarios en la Cámara de Diputados de la Nación se han hecho eco de guarismos semejantes, denunciando el consumo de 80 millones de litros de agua diarios (925 L/s). Cualquier proyecto standard de minería metalífera a cielo abierto en San Juan implicaría, de hecho, una demanda hídrica de un metro cúbico por segundo ${ }^{13}$ (RODRÍGUEZ PARDO, 2009; HACHER; 2007 y DIARIO LA VOZ, 2009, citados por IEZZI, 2011). Con respecto a la mina Gualcamayo, organizaciones ambientalistas señalan que en realidad consume $108 \mathrm{~L} / \mathrm{s}$ (NALM, 2012c), más del triple de agua de lo reconocido por el gobierno sanjuanino; consideramos que es un guarismo más cercano a la realidad, teniendo en cuenta el alto nivel de diseminación de los minerales y la baja ley aurífera $(1 \mathrm{~g} / \mathrm{t})$ del yacimiento. Si bien las cifras del consumo hídrico de Casposo, finalmente, serían poco significativas en comparación, evidentemente encierran un fuerte nivel de sub-registro; a falta de otras estimaciones alternativas, nos inclinamos a considerar al permiso provincial de extracción del recurso (12,5 L/s) como valor umbral mínimo para esta mina sanjuanina.

El Cuadro 2 presenta una síntesis de los resultados obtenidos a partir de la reconstrucción de la base de datos en relación a, por un lado, el volumen de extracción desagregado según yacimientos y minerales, y por el otro, el consumo hídrico de cada mina conforme a datos oficiales y estimaciones alternativas, para los casos en que esa información se hallaba disponible en aquellos casos para los cuales sólo existía una fuente, los datos fueron replicados-. Así pues, si se efectuara un cálculo conservador basado estrictamente en las cifras reconocidas por las empresas, la huella hídrica anual (parcial) de la minería metalífera en la Argentina se situaría en el orden de los 18.253.958,4 $\mathrm{m}^{3}$; si, por el contrario, se atendiera a las conclusiones arrojadas por estudios independientes, esos guarismos se elevarían a 75.957.562 $\mathrm{m}^{3}$, esto es, un $316,1 \%$ más. En proporción, los

\footnotetext{
13 En 2009, el periódico Los Andes de Mendoza denunció que el gobierno sanjuanino impidió la difusión en esa provincia de la revista Rumbos, donde un informe sobre la minería señalaba que cada proyecto insumía un millón de litros de agua por día (Diario La Voz, citado por IEZZI, 2011) -esto es, 1.157 L/s-
} 


\section{REA - Revista de estudos ambientais (Online) v.17, n. 2, p. 6-28, jul./dez. 2015}

mayores consumos hídricos corresponden a Bajo La Alumbrera $(43,9$ y $45,7 \%$, respectivamente), Veladero (10,8 y $38,4 \%$ ), Manantial Espejo (17,3 y $4,2 \%)$, Salar del Hombre Muerto (14,6 y 3,5\%), Gualcamayo (6 y $4,5 \%$ ) y Cerro Vanguardia (4,3 y $1,7 \%$ ).
Las diferencias más significativas entre estimaciones oficiales e independientes se verifican en Veladero (1.368,3\%), Bajo La Alumbrera $(333,1 \%)$, Gualcamayo $(208,6 \%)$, Casposo $(150 \%)$ y Cerro Vanguardia $(66,1 \%)$.

\begin{tabular}{|c|c|c|c|c|c|c|c|}
\hline Mina & PPA (kg) & $\begin{array}{l}\text { CHO } \\
\text { (L/s) }\end{array}$ & $\begin{array}{l}\mathrm{CH} \\
\text { (OE) } \\
\text { (L/s) }\end{array}$ & $\begin{array}{c}\mathrm{CHA}\left(\mathrm{m}^{3}\right) \\
(1)\end{array}$ & $\begin{array}{c}\mathrm{CHA}\left(\mathrm{m}^{3}\right) \\
(2)\end{array}$ & $\begin{array}{c}\text { CH/P } \\
\left(\mathrm{m}^{3} / \mathrm{kg}\right)(1)\end{array}$ & $\begin{array}{c}\text { CH/P } \\
\left(\mathrm{m}^{3} / \mathrm{kg}\right)(2)\end{array}$ \\
\hline \multirow{4}{*}{$\begin{array}{l}\text { Bajo La } \\
\text { Alumbrera }\end{array}$} & 185.000 .000 & \multirow[t]{4}{*}{254} & \multirow[t]{4}{*}{1.100} & \multirow[t]{4}{*}{8.010 .144} & \multirow[t]{4}{*}{34.689 .600} & 0,043 (cobre) & $0,19 \mathrm{~m}$ (cobre) \\
\hline & (cobre) & & & & & $381,6 \mathrm{~m}^{3}$ (oro) & $1.652,5$ (oro) \\
\hline & $\begin{array}{l}20.992,5 \\
\text { (oro) }\end{array}$ & & & & & \multirow[t]{2}{*}{169,5 (plata) } & \multirow[t]{2}{*}{733,8 (plata) } \\
\hline & $\begin{array}{l}47.272 \\
\text { (plata) }\end{array}$ & & & & & & \\
\hline Veladero & $\begin{array}{l}25.191 \text { (oro) } \\
41.207,5 \\
\text { (plata) }\end{array}$ & 63 & 925 & 1.986 .768 & 29.170 .800 & $\begin{array}{c}78,9 \text { (oro) } \\
48,2 \text { (plata) }\end{array}$ & $\begin{array}{c}1.158 \text { (oro) } \\
707,9 \text { (plata) }\end{array}$ \\
\hline Cerro Negro & 12.440 (oro) & 12,9 & 12,9 & $406.814,4$ & $406.814,4$ & 32,7 (oro) & 32,7 (oro) \\
\hline $\begin{array}{l}\text { Cerro } \\
\text { Vanguardia }\end{array}$ & $\begin{array}{l}6.562,1 \text { (oro) } \\
66.865 \\
\text { (plata) }\end{array}$ & 25,1 & 41,7 & $791.553,6$ & $1.315 .051,2$ & $\begin{array}{l}120,6 \text { (oro) } \\
11,8 \text { (plata) }\end{array}$ & $\begin{array}{l}200,4 \text { (oro) } \\
19,7 \text { (plata) }\end{array}$ \\
\hline Gualcamayo & $\begin{array}{l}4.665 \text { (oro) } \\
242,6 \text { (plata) }\end{array}$ & 35 & 108 & 1.103 .760 & 3.405 .888 & $\begin{array}{c}236,60 \text { (oro) } \\
4.549,7 \text { (plata) }\end{array}$ & $\begin{array}{c}730 \text { (oro) } \\
14.039,1 \\
\text { (plata) }\end{array}$ \\
\hline Casposo & $\begin{array}{l}2.907,9 \text { (oro } \\
\text { equivalente) }\end{array}$ & 5 & 12,5 & 157.680 & 394.200 & $\begin{array}{l}54,22 \text { (oro } \\
\text { equivalente) }\end{array}$ & $\begin{array}{l}135,5 \text { (oro } \\
\text { equivalente) }\end{array}$ \\
\hline $\begin{array}{l}\text { Manantial } \\
\text { Espejo }\end{array}$ & $\begin{array}{l}2.065 \text { (oro) } \\
119.579,5 \\
\text { (plata) }\end{array}$ & 100 & 100 & 3.153 .600 & 3.153 .600 & $\begin{array}{c}1.527,2 \text { (oro) } \\
26,4 \text { (plata) }\end{array}$ & $\begin{array}{c}1.527,2 \text { (oro) } \\
26,4 \text { (plata) }\end{array}$ \\
\hline $\begin{array}{l}\text { Salar del } \\
\text { Hombre } \\
\text { Muerto }\end{array}$ & $\begin{array}{l}28.500 .000 \\
\text { (litio) }\end{array}$ & 84,4 & 84,4 & $2.661 .638,4$ & $2.661 .638,4$ & 0,094 (litio) & 0,094 (litio) \\
\hline Sub-total & $\begin{array}{l}185.000 .000 \\
\text { (cobre) } \\
349.990,1 \\
\text { (oro y plata) } \\
28.500 .000 \\
\text { (litio) }\end{array}$ & 579,4 & $2.384,5$ & $18.253 .958,4$ & 75.957 .562 & $* * * * * *$ & $* * * * * *$ \\
\hline $\begin{array}{l}\text { San José- } \\
\text { Huevos } \\
\text { Verdes }\end{array}$ & $\begin{array}{l}2.379,2 \text { (oro) } \\
147.367,2 \\
\text { (plata) }\end{array}$ & $\mathrm{s} / \mathrm{d}$ & $s / d$ & $* * * * * *$ & $* * * * * *$ & $* * * * * *$ & $* * * * * *$ \\
\hline Martha & $\begin{array}{l}105.740 \\
\text { (oro) } \\
83.970 \\
\text { (plata) }\end{array}$ & $\mathrm{s} / \mathrm{d}$ & $s / d$ & $* * * * * *$ & $* * * * * *$ & $* * * * * *$ & $* * * * * *$ \\
\hline$\underline{\text { Total }}$ & $\begin{array}{l}185.000 .000 \\
\text { (cobre) } \\
689.446,5 \\
\text { (oro y plata) } \\
28.500 .000 \\
\text { (litio) }\end{array}$ & 579,4 & $2.384,5$ & $18.253 .958,4$ & 75.957 .562 & $* * * * * *$ & $* * * * * *$ \\
\hline
\end{tabular}

Referencias: PPA: producción promedio anual. $\mathrm{CHO}(\mathrm{L} / \mathrm{s})$ : consumo hídrico oficial (litros por segundo). $\mathrm{CH}(\mathrm{OE})$ (L/s): Consumo hídrico (otras estimaciones) (litros por segundo). $\mathrm{CHA}\left(\mathrm{m}^{3}\right)$ (1): Consumo hídrico anual (metros cúbicos) (1). CHA $\left(\mathrm{m}^{3}\right)(2)$ : Consumo hídrico anual (metros cúbicos) (2). CH/P $\left(\mathrm{m}^{3} / \mathrm{kg}\right)(1)$ : consumo hídrico sobre producción (metros cúbicos sobre kilogramo) (1). $\mathrm{CH} / \mathrm{P}\left(\mathrm{m}^{3} / \mathrm{kg}\right)(2)$ : Consumo hídrico sobre producción (metros cúbicos sobre kilogramo) (2).

Fuente: elaboración propia (2015) sobre la base de: CAEM (2012); Nacif (2014); PetrolNews.Net (2009); Barrick (2014); San Juan (2013a, 2013b, 2013c); Linares (2011); El Inversor On Line (2014); InfoMine (2014); Mining Press Argentina (2007, 2015a, 2015b); García de las Tongas (2009); OPI Santa Cruz (2010, 2011); NALM (2012a, 2012b, 2012c, 2013a, 2013b); Rodríguez Pardo (2009); lezzi (2011); Oroplata S.A. (2010); OCMAL (2015). 


\section{REA - Revista de estudos ambientais (Online) v.17, n. 2, p. 6-28, jul./dez. 2015}

Otro resultado significativo es que, atendiendo exclusivamente a las cifras aceptadas por las empresas y/o legitimadas por los gobiernos provinciales, el volumen de agua virtual contenido en un gramo de oro rebasa holgadamente los 18 litros promedio, situándose, en el mejor de los casos, en 32,7/54,2 litros (Cerro Negro y Casposo), y en el peor, en 381/1.527 litros (Bajo La Alumbrera y Manantial Espejo). Si se consideran las estimaciones alternativas, los extremos oscilarían entre 135/200 litros (Casposo y Cerro Vanguardia) y 1.158/1.652 litros (Veladero y Bajo La Alumbrera). EI caso de Cerro Vanguardia es paradigmático, toda vez que ambas estimaciones refutan las aseveraciones de la propia empresa: la misma, en su publicación corporativa Oro del Sur, afirmaba que cada 31,1 gramos de oro extraídos del yacimiento se consumían apenas 376,3 litros de agua (MINING CLUB, 2013). Sin embargo, los cálculos basados en cifras reconocidas por la propia minera dan cuenta de $3.751 \mathrm{~L}$ (un $896,8 \%$ más), y los guarismos derivados de su informe hidrogeológico ascienden a $6.232 \mathrm{~L}(1.556,1 \%)$. Si se contrasta la totalidad de la extracción aurífera con la sumatoria de los respectivos consumos hídricos oficiales e independientes, puede concluirse que la obtención de un gramo de oro requeriría, en promedio, entre 244 y 1.015 litros de agua. Finalmente, el volumen de agua virtual condensado en una tonelada de litio sería de 93.991 L, en tanto que en el caso del cobre fluctuaría entre 43.298 y 187.511 L, dependiendo de qué fuente sea considerada válida para la realización del cálculo.

La relación de la minería metalífera con la sangría de agua virtual en la Argentina merece ser cuidadosamente analizada. Si bien puede argüirse que los resultados obtenidos en este trabajo representarían una proporción ínfima de los flujos hídricos 'exportados' por la Argentina -entre el 0,04 y el $0,15 \%$ de los 52.000 millones de metros cúbicos calculados por Chapagain $y$ Hoekstra (2004) y entre el 0,02 y el $0,06 \%$ de los 19.000 millones estimados por Rodríguez-Iturbe (VIANO, 2013)-, esto puede conducir a conclusiones engañosas, y así enmascarar la enorme huella que la minería aurífera deja sobre los recursos hídricos argentinos. Como se comentó anteriormente, el principal motor de las 'exportaciones' nacionales de agua virtual es la soja transgénica, cultivo cuya producción demanda entre 1.100 y 1.250 metros cúbicos por tonelada (PENGUE, 2006; MERENSON,
2011). Ahora bien, tomando como base el consumo de agua oficial de Cerro Negro, el yacimiento con menores requerimientos hídricos $\left(32,7 \mathrm{~m}^{3} / \mathrm{kg}\right)$, extraer una tonelada de oro requeriría como mínimo unos $32.697,3 \mathrm{~m}^{3}$. En términos relativos, la huella hídrica de la minería del oro sería, en el mejor de los casos, 25 veces superior a la de la soja ${ }^{14}$.

Las siderales cifras del consumo de agua de la minería metalífera tampoco dejan lugar a dudas acerca del inestimable (e irreversible) impacto de la actividad sobre el recurso. Si se aceptan como base las estimaciones de la Organización Mundial de la Salud (ONU, 2010), que señalan que las necesidades esenciales promedio de consumo hídrico per cápita rondarían los 80 litros/día, y se contrastan estos guarismos con la ingente demanda de las mineras, cualquiera de los proyectos mencionados consume, en un solo segundo, un volumen equivalente a (según el caso) entre el 15,6 y el $1.375 \%$ del agua utilizada diariamente por una persona. Así pues, un cálculo conservador arrojaría como resultado que la actividad representa el $46,9 \%$ del consumo

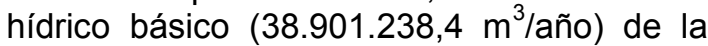
población (1.322.837 habitantes) de las tres provincias consideradas (Catamarca, Santa Cruz y San Juan), en tanto que, tomando como punto de partida las estimaciones alternativas, esa demanda sería equivalente al $195,3 \%$. Si los datos fueran desagregados según jurisdicciones, el consumo de agua de los tres yacimientos sanjuaninos representaría entre el 16,3 y el $20 \%$ de la demanda hídrica esencial (19.886.514 $\mathrm{m}^{3}$ /año) de la población de esa provincia (681.045 habitantes); sólo tres minas acapararían entre el 54,4 y el $60,9 \%$ el agua utilizada (7.999.748,8 $\mathrm{m}^{3} /$ año $)$ por los 273.964 habitantes del territorio santacruceño; y apenas dos yacimientos absorberían entre el 99,4 y el $347,8 \%$ de los requerimientos básicos anuales de consumo $\left(10.740 .577,6 \mathrm{~m}^{3}\right)$ de los 367.828 habitantes de Catamarca ${ }^{15}$. Si bien el nivel de disponibilidad hídrica de la Argentina es, en términos generales, relativamente elevado, la minería metalífera extrae agua de áreas áridas y semiáridas -donde el recurso escasea-, arrebatándoselo a las

\footnotetext{
${ }^{14}$ En el otro extremo, la huella hídrica de una tonelada de oro en Bajo La Alumbrera oscila entre $381.532,9 \mathrm{~m}^{3} \mathrm{y}$ $1.669 .652,6 \mathrm{~m}^{3}$, siendo entre 304 y 1.335 veces mayor a la de una tonelada de soja.

${ }_{15}$ Cifras de población del último Censo Nacional de Población, Hogares y Viviendas (2010) (INDEC, 2013).
} 


\section{REA - Revista de estudos ambientais (Online) \\ v.17, n. 2, p. 6-28, jul./dez. 2015}

comunidades locales para drenarlo al exterior.

Otra cuestión no menos significativa apunta al valor económico atribuido al agua. Si bien lejos estamos de pretender atribuir al recurso hídrico la representación puramente mercantilista que a menudo hacen de él los organismos internacionales respecto del enfoque del 'agua virtual' (COLLADO; SAAVEDRA, 2010; BELTRÁN; VELÁZQUEZ, 2014), o de reducir su naturaleza a la de estrictamente un factor de producción -más bien tendemos a considerarlo, ante todo, un derecho humano inalienable-, resulta interesante dimensionar empíricamente la magnitud del despojo concretado por las mineras transnacionales. Costanza (1997) (citada por MERENSON, 2011) estima que en la actualidad el valor del metro cúbico de agua rondaría los U\$S 0,67. Si se considera este dato en función de los años de actividad de cada yacimiento y el volumen hídrico consumido por éstos en ese lapso, el valor total de las 'exportaciones' argentinas de agua virtual asociadas a la minería metalífera oscilaría entre 162 y 662 millones de dólares (Cuadro 3). Lo anterior contrasta respecto del exiguo (y en algunos casos irrisorio) costo impuesto por los gobiernos provinciales a las empresas mineras por el uso intensivo del recurso hídrico. En Santa Cruz, los ingresos que en 2008 la provincia obtuvo de la actividad en concepto de canon por la utilización del agua ascendieron a 16 millones de pesos (OPI SANTA CRUZ, 2011), es decir, 3,5 millones de dólares, conforme a la cotización de la moneda estadounidense en ese año. En San Juan, cada minera -a excepción de Barrick Gold (Veladero se encuentra exento de esa carga retributiva) paga sólo 90 pesos diarios (NALM, 2013b) por su irrestricto consumo hídrico -en total, menos de 4.000 dólares/año, a la cotización actual ${ }^{16}$-. En Catamarca, el valor del metro cúbico de agua que el gobierno provincial impone a las mineras es de apenas $\$ 0,01$, cifra insignificante $^{17}$ que, por añadidura, ni siquiera es erogada por la concesionaria de

\footnotetext{
${ }^{16}$ Al momento de desarrollar esta investigación (abril de 2015), la cotización oficial del dólar estadounidense en la Argentina era de 8,86 pesos moneda nacional (BCRA, 2015).

17 En 1978, el Manual de la Oficina de Minas de los Estados Unidos establecía el valor del metro cúbico de agua para la actividad en 10 centavos de dólar (RODRÍGUEZ PARDO, 2009), esto es, un valor casi 100 veces superior al fijado en pleno siglo XXI por Catamarca (1 centavo de peso argentino).
}

Salar del Hombre Muerto (NALM, 2012b) ${ }^{18}$. A la luz de estos datos, queda claro que las empresas transnacionales y las firmas globales del sector protagonizan en la Argentina un auténtico saqueo, no sólo del cobre, el oro, la plata y otros minerales, sino también del agua, en clave de acumulación por desposesión.

No menos importante es el hecho que el mapa de las exportaciones argentinas de minerales metálicos coincida notablemente con los flujos mundiales de transferencia de agua virtual: en efecto, y según estadísticas oficiales (ARGENTINA, 2010), en 2009 los principales destinos $83,3 \%$ del total- de la extracción metalífera de la Argentina fueron Alemania, Corea del Sur, Filipinas, Japón y China, todas ellas naciones importadoras netas de recursos hídricos. Sólo los tres primeros casos Alemania $(31,7 \%)$, Corea del Sur $(23,3 \%)$ y Filipinas (13,6\%)- concentraban el 68,6\%. Si bien el protagonismo de estos dos últimos países obedecería en principio tanto a su vertiginoso crecimiento económico como al hecho de que el continente asiático representa actualmente el mayor mercado para la comercialización de metales de alto valor, el caso de Alemania requiere una mención especial: pese a no padecer déficit alguno en cuanto a la disponibilidad de recursos hídricos, este país 'importa' cuantiosos volúmenes de agua virtual (PARADA-PUIG, 2012), lo cual revela una clara y deliberada estrategia imperialista de ahorro y externalización de costos en el uso del vital elemento a expensas de otras naciones.

Otra cuestión primordial a considerar atañe al origen geográfico de las corporaciones mineras transnacionales que operan en la Argentina, es decir, Suiza, Canadá, Estados Unidos y Australia: en ese conjunto, Suiza representaría una situación similar a la de Alemania -no sufre escasez de agua, pero igualmente la drena de otras naciones-, en tanto que Canadá, Estados Unidos y Australia constituyen importantes exportadores netos de agua virtual, siendo paralelamente los principales productores mineros del mundo. Si se tiene en cuenta que las empresas transnacionales, al

\footnotetext{
18 La empresa estadounidense que explota Salar del Hombre Muerto rehúsa pagar ese irrisorio precio por el agua, amparándose en una exención otorgada en 1991 y ratificada en 1994. El caudal de agua utilizado es incluso ignorado por la Subsecretaría de Recursos Hídricos; cuando el gobierno provincial reclamó el pago del tributo, debió solicitarle a la minera información acerca de su propio consumo hídrico (NALM, 2013b).
} 
organizar los flujos productivos y comerciales a nivel mundial, hacen lo propio con los dispositivos que regulan las transferencias de bienes ambientales entre países -entre ellos el agua- (MACHADO ARAOZ, 2010), es evidente que uno de los rasgos fundamentales de la estrategia de acumulación de las corporaciones mineras norteamericanas y australianas consiste en desplazar, a través de sus filiales y subsidiarias, la extracción metalífera a la periferia del sistema capitalista, imponiéndole a los países del Sur global una doble función en el marco de la división internacional del trabajo: la especialización minera y la especialización hidrológica.

Cuadro 3 - Exportaciones de agua virtual asociadas a la minería metalífera, en volumen $\left(\mathrm{m}^{3}\right)$ y valor (USS), discriminadas según cálculos oficiales (1) y estimaciones alternativas (2), por yacimientos y años de actividad. Argentina (1997-2014)

\begin{tabular}{|c|c|c|c|c|c|}
\hline Mina & $\begin{array}{l}\text { Años en } \\
\text { actividad }\end{array}$ & $\begin{array}{l}\text { Exportación de } \\
\text { agua virtual }\left(\mathrm{m}^{3}\right) \\
\text { (1) }\end{array}$ & $\begin{array}{c}\text { Exportación de } \\
\text { agua virtual }\left(\mathrm{m}^{3}\right) \\
(2)\end{array}$ & $\begin{array}{l}\text { Exportación de } \\
\text { agua virtual } \\
\text { (U\$S) (1) }\end{array}$ & $\begin{array}{l}\text { Exportación de agua } \\
\text { virtual (U\$S) (2) }\end{array}$ \\
\hline $\begin{array}{l}\text { Bajo La } \\
\text { Alumbrera }\end{array}$ & 17 & 136.172 .448 & 589.723 .200 & $91.235 .540,2$ & 395.114 .544 \\
\hline Veladero & 10 & 19.687 .680 & 291.708 .000 & 13.190.745,6 & 195.444 .360 \\
\hline Cerro Negro & 1 & $406.814,4$ & $406.814,4$ & $272.565,7$ & $272.565,7$ \\
\hline $\begin{array}{l}\text { Cerro } \\
\text { Vanguardia }\end{array}$ & 16 & $12.664 .857,6$ & $21.040 .819,2$ & $8.485 .454,6$ & $14.097 .348,9$ \\
\hline Gualcamayo & 5 & 5.518 .800 & 17.029 .440 & 3.697 .596 & $11.409 .724,8$ \\
\hline Casposo & 4 & 630.720 & 1.576 .800 & $422.582,4$ & 1.056 .456 \\
\hline $\begin{array}{l}\text { Manantial } \\
\text { Espejo }\end{array}$ & 6 & 18.921 .600 & 18.921 .600 & 12.677 .472 & 12.677 .472 \\
\hline $\begin{array}{l}\text { Salar del } \\
\text { Hombre }\end{array}$ & 18 & $47.909 .491,2$ & $47.909 .491,2$ & $32.099 .359,1$ & $32.099 .359,1$ \\
\hline Total & & $241.912 .411,2$ & $988.316 .164,8$ & $162.081 .315,5$ & $662.171 .830,4$ \\
\hline
\end{tabular}
2011).

Lo anterior permite a ciertos países centrales externalizar los enormes impactos ambientales de la actividad (entre ellos, el agotamiento del vital elemento) $y$, paralelamente, coloca a las grandes empresas transnacionales del sector en una posición estratégica: por un lado, éstas logran controlar y coordinar a escala global una parte de los flujos internacionales de agua virtual, remesando una parte hacia los países donde se hallan sus principales nichos de comercialización y/o se desarrollan sus procesos productivos de mayor valor agregado; por el otro, redirigen el remanente hacia sus propias naciones de origen, en un esquema en el cual el desplazamiento del centro geográfico de gravedad de la minería metalífera hacia la periferia del sistema capitalista implica un significativo ahorro de agua en Estados Unidos, Canadá y Australia, contribuyendo así a aliviar la pérdida del recurso que para estos países suponen las transferencias hídricas al exterior. Los resultados obtenidos por este trabajo nos conducen entonces a coincidir respecto de la postura de Machado Araoz (2010), quien sostiene que las grandes mineras transnacionales que controlan oligopólicamente el mercado mundial del sector operan como correas de transmisión de las desigualdades ecológicas entre países proveedores de minerales -y con ellos, de agua y energía- y sociedades que los consumen, obteniendo por tales 'servicios' enormes ganancias económicas.

Queda abierto un inquietante interrogante: en virtud de la crisis social y ambiental desencadenada por el desmesurado consumo hídrico del puñado de minas actualmente en operación, ¿qué sucederá con las reservas de agua dulce de las áreas cordilleranas en particular cuando se concrete la explotación del casi centenar de yacimientos que -sólo del lado argentinose encuentran en etapa de exploración, prospección y factibilidad? Sólo la provincia de San Juan cuenta con más de cuarenta proyectos metalíferos (Pascua Lama, Penélope, Batidero-Vicuña, Pachón, etc.), y la de Catamarca, con catorce (Agua Rica, etc.); a estos deben añadirse casos como los de Santa Cruz (Alto Rico, Río Oro, El Zeballos, La Marcelina, Cerro Moro, Cerro Puntudo, La Josefina etc.), Salta (Arizaro- 
Lindero, Diablillos, Río Grande) y de provincias donde la resistencia social ha impedido el inicio formal de la actividad Mendoza (San Jorge, Paramillos), Chubut (EI Desquite, Navidad), Río Negro (Calcatreu), Jujuy (Pirquitas) y La Rioja (Famatina)-.

\section{Conclusiones}

Operando vía el reparto a escala mundial de los vectores de la división internacional del trabajo, el orden global impone funciones más o menos evidentes a países y lugares, las cuales se traducen en la especialización en tal o cual actividad económica). Solapadamente, ese orden global también asigna funciones ecológicas mucho menos obvias (proveer de biomasa o intangibles ambientales al mercado mundial), complejizando así los mecanismos de subordinación que los países centrales imponen a los países periféricos. Orientadas a exacerbar la mercantilización de la naturaleza, las formas extractivistas de explotación del territorio constituyen tanto un ariete para la acumulación por desposesión como una amenaza para el patrimonio ambiental; así pues, un elemento esencial para la vida como el agua deja de constituir un mero valor de uso para convertirse, cada vez más, en un valor de cambio. El recurso hídrico se transforma en un capital fijo que, pese a hallarse materialmente enraizado en los ecosistemas de cada territorio, circula permanentemente vía los flujos del comercio internacional, haciendo posible el desarrollo de ciertas actividades económicas a través de la transferencia de valor, sufriendo en contrapartida un ostensible desgaste cuantitativo y cualitativo.

El reciente boom de la mega-minería metalífera a cielo abierto en la Argentina constituye un inequívoco ejemplo de esa racionalidad: por un lado, encarna a un uso moderno del territorio devenido racional únicamente para los agentes beneficiados por ese modelo de organización espacial (las empresas transnacionales), pero irracional para todos los demás actores; por el otro, reúne todas los atributos que permiten considerarlo como una expresión pura y paradigmática del orden de las verticalidades: así lo demuestran ciertos rasgos intrínsecos al desenvolvimiento de la actividad, tales como la mundialización del capital, la producción globalizada, las normas internacionales, la obediencia a los intereses hegemónicos externos y a la lógica del mercado, la corporatización del territorio, la creación de desorden en el ámbito local, el saqueo de riquezas nacionales y 'recursos naturales', y la valoración/uso del territorio en términos estrictamente pragmáticos $y$ económicos. En relación a esta última cuestión, al tratarse de un modelo de acumulación diseñado para ser indiferente al entorno socio-ambiental donde opera, el agua queda reducida a la condición de mero recurso a ser apropiado, acopiado y explotado, subalternizando así a aquellas racionalidades locales que la entienden como fuente básica para el sustento de la vida.

Queda expuesta, asimismo, la insoslayable relación entre modelo minero y acumulación por desposesión; la forma que asume el desarrollo de la actividad en la Argentina expresa todas características arquetípicas de ese fenómeno, desde la enajenación del patrimonio geológico nacional, la privatización de tierras y el saqueo de los recursos minerales, hasta el despojo del derecho a la salud de la población, pasando por cuestiones objeto de pormenorizado análisis en este trabajo: la depredación/degradación a gran escala del patrimonio ambiental, y la intensificación de la transferencia de capacidad de carga y servicios ecológicos hacia, por un lado, países mineros tradicionales (Canadá, Estados Unidos y Australia) donde se sitúan las casas matrices de las empresas implicadas, y por el otro, hacia naciones donde esas mismas corporaciones explotan los principales nichos de mercado para la comercialización de metales.

Obstando la incompletud de la información empírica, las dificultades para acceder a la misma, la tenaz insistencia corporativa por enmascararla u oscurecerla y las discrepancias verificadas entre las distintas fuentes de datos, la gigantesca huella hídrica de la minería metalífera 'argentina' (especialmente, la aurífera) es inocultable, aunque pueda verse relativizada o matizada por su ínfima participación en las voluminosas 'exportaciones' argentinas de agua virtual. La crisis hídrica que atraviesan las provincias mineras -sobre todo Catamarca y San Juan- revela a su vez cómo el agua que le es negada a buena parte de las comunidades locales acaba siendo drenada hacia el exterior bajo la forma de cobre, oro y plata. En los dos últimos casos, el vital recurso sólo servirá para satisfacer el inútil consumo suntuario de joyas por parte de los sectores sociales de 
mayor poder adquisitivo, así como también para permitir la continuidad de la acumulación de reservas en las bóvedas de los organismos multilaterales de crédito y los bancos centrales de las grandes potencias. En resumidas cuentas, la minería metalífera ha sido llamada a reforzar la función que el orden global parece haberle unilateralmente asignado a la Argentina: amortiguar los excesos del sistema capitalista mundial a partir del engrosamiento de la creciente deuda ecológica que, históricamente, el Norte siempre ha acumulado a expensas del Sur.

\title{
7 Global Order and Accumulation by Dispossession. 'Virtual Water' Exportation and Water Footprint of Metal Mining in Argentina (1997-2014)
}

\begin{abstract}
Aimed at restructuring countries and places roles in function of the interests of capital, global order is a hegemonic, economic, political and territorial social arrangement based on the accumulation by dispossession. Coordinated and implemented by transnational corporations, and supported by the governments of the peripheral countries, this plunder is expressed in a myriad of forms and facets: among them are the increasing rise won by extractivism in Latin America, a phenomenon that arouses growing concern due both degradation as well as the pulling and transfer abroad of environmental intangible as the "virtual water". In light of this situation, the goal of this work is to analyze the relatively recent boom of megametal open pit mining in Argentina, to comply with two complementary objectives: assessing the activity's water footprint and the role it plays in the national export of "virtual water", as well as accounting the social and environmental impact of the strategies of appropriation of water resources deployed by transnational mining (and legitimized by the Nation-State), demonstrating its links to the worsening problem of access to this vital element in the provinces implicated.
\end{abstract}

Keywords: Accumulation by dispossession; Virtual water; Water footprint; Metal mining; Argentina.

\section{Bibliografía}

ALLAN, J. A. Fortunately there are substitutes for water otherwise our hydro-political futures would be impossible. Priorities for water resources allocation and management, London: ODA, 1993.

ALLAN, J. A. Virtual water: achieving a nonhydrocentric understanding of water allocation and management. Stockholm: Stockholm International Water Institute (SIWI), 2003.

ARGENTINA. Minería en números, 2008. Buenos Aires: Secretaría de Minería, Ministerio de Planificación Federal, Inversión Pública y Servicios, 2008.

ARGENTINA. Informe sectorial. Sector de minería. Buenos Aires: Subsecretaría de Comercio Internacional, Ministerio de Relaciones Exteriores, Comercio Internacional y Culto, 2010.

ARGENTINA. Minería en números, 2011. Buenos Aires: Secretaría de Minería, Ministerio de Planificación Federal, Inversión Pública y Servicios, 2012.

BARRICK. Proyecto Veladero. Disponible en: <http://barricklatam.com/veladero/barrick/2014-0514/154200.html>. Acceso en: mar. 2014.
BASUALDO, F.; MANZANELLI, P. Misterios mineros en la región. Transformaciones estructurales e influencia política del capital extranjero en Honduras y la Argentina. Buenos Aires: IADE, 2011.

BCRA. (2015). Estadísticas. Series cambiarias. Cotizaciones, por fecha. Banco Central de la República Argentina. Disponible en: $<$ http://www.bcra.gov.ar/Estadisticas/estser03050 7.asp>. Acceso en: abr. 2015.

BELTRÁN, M. J.; VELÁZQUEZ, E. ¿Qué oculta el agua virtual? Análisis crítico de las ideas subyacentes del concepto de agua virtual. In: VIII Congreso Ibérico sobre Gestión y Planificación del Agua. Lisboa: Universidade Luisíada Editora, 2014. p. 421-434.

BERARDI, A. L. Minería argentina: de ganancias macroeconómicas y pérdidas socioambientales. In: LIBERALI, A. M.; GEJO, H. O. (Comp.). La Argentina como geografía. Procesos productivos e impacto social (1990-2008). Buenos Aires: UNMDP-UNLu-CEAvH-UGAL-UGI, 2010.

CACACE, G. P.; GÓMEZ, M. E.; MORINA, J. O. Expoliación de recursos naturales $y$ neocolonialismo en la Argentina del Siglo XXI: el caso de la gran minería metalífera. Meridiano Revista de Geografía, n. 1, 2012. Disponible en: 
<http://www.revistameridiano.org/n1/08>. Acceso en: 10 nov. 2014.

CACACE, G. P.; GÓMEZ, M. E.; MORINA, J. O. La megaminería en la Argentina del siglo XXI: saqueo extractivista neocolonial. In: CACACE, $G$. P; GÓMEZ, M. E.; MORINA, J. O.; SUEVO. G. E. (Comp.). Geografías regionales y extractivismo en la Argentina de los bicentenarios. Luján: Universidad Nacional de Luján, 2013. p. 398-441.

CAEM. Manual de minería. Ejemplos en la Argentina. Disponible en: http://www.manualdemineria.com/index.php?title= Ejemplos_en_Argentina. 2012.

CHAPAGAIN. A.; HOEKSTRA, A. Virtual water trade: a quantification of virtual water flows in relation to the international trade of agricultural products. Delft: UNESCO-IHE, 2003.

CHAPAGAIN, A.; HOEKSTRA, A. Water footprints of nations. Vol. 1 y 2. Disponible en: $<$ http://www.waterfootprint.org/?page=files/Publica tions>. Acceso en: 2004.

COLLADO, B.; SAAVEDRA, I. P. Agua virtual en los países en desarrollo. Zaragoza: Universidad de Zaragoza, 2010.

EL INVERSOR ON LINE. Casposo incrementa un $20 \%$ su producción de oro a partir de la explotación subterránea. 2014. Disponible en: <http://elinversoronline.com/2014/11/casposoincrementa-un-20-su-produccion-de-oro-a-partirde-la-explotacion-subterranea/>. Acceso en: 10 mar. 2015.

FAO. Value of virtual water in food: principles and virtues. Roma: Naciones Unidas, 2003.

FRECHERO, J. I. Neoextractivismo e inserción internacional. Hacia una Argentina económica y ecológicamente dependiente. In: FERNÁNDEZ EQUIZA, A. M. (Comp.). Territorios, economía internacional y conflictos socioambientales. Tandil: IGEHCS (CONICET/UNCPBA), 2013. p. 59-101.

GARCÍA DE LAS TONGAS, E. "El consumo de agua de Cerro Vanguardia está muy por debajo de lo autorizado por Recursos Hídricos de la provincia de Santa Cruz". Solicitada de la Minera Cerro Vanguardia en el Diario Tiempo Sur, 2009. Disponible <http://www.tiemposur.com.ar/nota/7900-cerrovanguardia-sobre-utilizaci\%C3\%B3n-delagua.html>. Acceso en: 15 mar. 2015.

GARIBAY OROZCO, C. Paisajes de acumulación minera por desposesión campesina en el México actual. In: DELGADO-RAMOS, G. C. (Coord.). Ecología política de la minería en América Latina. Aspectos socioeconómicos, legales y ambientales de la mega minería. México:
Universidad Autónoma de México, 2010. p. 133182.

GÓMEZ LENDE, S. División territorial del trabajo y medio técnico-científico-informacional. Verticalidades y horizontalidades de la minería metalífera argentina. Revista Geográfica Venezolana, Mérida, v. 46, n. 4, p. 253-288, 2005.

GÓMEZ LENDE, S. Guerra de lugares en Argentina: perspectivas de análisis y ejemplos empíricos. Revista Universitaria de Geografía, Bahía Blanca, v. 19, p. 139-177, 2010.

GÓMEZ LENDE, S.; VELÁZQUEZ, G. Á. División del trabajo y productividad espacial. La minería metalífera en la Provincia de Catamarca, Argentina. Revista Geográfica Venezolana, Mérida, v. 45, n. 2. p. 165-197, 2004.

GÓMEZ LENDE, S.; VELÁZQUEZ, G. Á. Orden global y territorio, verticalidades y horizontalidades. El caso de la minería metalífera en Argentina (1998-2007). In: MORINA, J. O. (Dir./Comp). Cuestiones regionales en la Argentina al comenzar el Siglo XXI. Consecuencias sociales, económicas y ambientales de la explotación de recursos naturales. Luján: UNLu, 2008. p. 55-102.

GOTTMANN, J. The evolution of the concept of territory. Information sur les Sciences Sociales, París, v. 14, n. 2, p. 29-47, 1975.

GRAJALES QUINTERO, A.; JARAMILLO ROBLEDO, Á.; CRUZ CERÓN, G. Los nuevos conceptos sobre "agua virtual" y "huella hídrica" aplicados al desarrollo sostenible: implicaciones de la agricultura en el consumo hídrico. Agronomía, Bogotá, v. 16, n. 1, p. 7-21, 2008.

GUDYNAS, E. Diez tesis urgentes sobre el nuevo extractivismo. Contextos y demandas bajo el progresismo sudamericano actual. In: VVAA: Extractivismo, Política y Sociedad. Quito: Centro Andino de Acción Popular (CAAP)-Centro Latinoamericano de Ecología Social (CLAES), 2009. p. 187-225.

GUDYNAS, E. El nuevo extractivismo progresista en América del Sur. Tesis sobre un viejo problema bajo nuevas expresiones. In: VVAA: Colonialismo del Siglo XXI. Barcelona: Icaria, 2011. p. 75-92.

HAESBAERT, R. Território e multiterritorialidade: um debate. GEOgraphia, Fluminense, v. 9, n. 17, p. 19-45, 2008.

HARVEY, D. Los límites del capitalismo y la teoría marxista. Buenos Aires: Fondo de Cultura Económica, 1988.

HARVEY, D. La condición de la posmodernidad. Una investigación acerca de 
los orígenes del cambio cultural. Buenos Aires: Amorrortu, 1990.

HARVEY, D. EI nuevo imperialismo. Madrid: Akal, 2004.

HOEKSTRA, A.; HUNG, P. Virtual water trade. A quantification of virtual water flows between nations in relation to international crop trade. Value of water research report series, 11, 2002.

IEZZI, L. E. Minería aurífera a cielo abierto en Argentina. El caso del emprendimiento Veladero, provincia de San Juan. La Plata: Universidad Nacional de La Plata, 2011.

INDEC. Extracción de minerales de minas y canteras. Total del país. Año 2009. Buenos Aires: Instituto Nacional de Estadística y Censos, 2010.

INDEC. Censo Nacional de Población Hogares y Viviendas 2010. Resultados definitivos, por provincias, departamentos y localidades. Buenos Aires: Instituto Nacional de Estadística y Censos, 2013.

INFOMINE. Gualcamayo pasa de 120.000 a 180.000 onzas en un año. 2014. Disponible en: <http://noticiasmineras.mining.com/2014/11/06/arg entina-gualcamayo-pasa-de-120-000-a-180-000onzas-en-un-ano/>. Acceso en: 2 mar. 2015.

LINARES, E. Mapa del saqueo del oro argentino. 2011. Disponible en: <http://www.noalamina.org/ >. Acceso en: 2 mar. 2015.

LLAMAS MADURGA, M. R. Los colores del agua, el agua virtual y los conflictos hídricos. Madrid: Real Academia de Ciencias Exactas, Físicas y Naturales, 2005.

MACHADO ARAOZ, $H$. Auge minero $y$ dominación neocolonial en América Latina. Ecología política de las transformaciones socioterritoriales neoliberales. In: XXVII Congreso de la Asociación Latinoamericana de Sociología. Buenos Aires: ALS, 2009a.

MACHADO ARAOZ, H. Minería transnacional, conflictos socioterritoriales y nuevas dinámicas expropiatorias. El caso de Minera La Alumbrera. In: SVAMPA, M; ANTONELLI, M. A (Ed.). Minería transnacional, narrativas del desarrollo $y$ resistencias sociales. Buenos Aires: Biblos, 2009b. p. 205-228.

MACHADO ARAOZ, $H$. Agua y minería transnacional. Desigualdades hídricas e implicaciones biopolíticas. Proyección, Buenos Aires, n. 9, p. 61-90, 2010.

MACHADO ARAOZ, H.; SVAMPA, M.; VIALE, E.; GIRAUD, M.; WAGNER, L.; ANTONELLI, M.; GIARRACCA, N.; TEUBAL, M. 15 mitos y realidades de la minería transnacional en la
Argentina. Guía para desmontar el imaginario prominero. Buenos Aires: El ColectivoHerramienta, 2011.

MANDEL, E. Tratado de economía marxista. México, D.F: Fondo de Cultura Económica, 1969.

MARTÍNEZ ALIER, J.; OLIVERAS, A. ¿Quién debe a quién? Deuda ecológica y deuda externa. Barcelona: Icaria, 2003.

MARX, K. El capital. México, D.F: Fondo de Cultura Económica, 1968.

MERENSON, C. Estimación del pasivo ambiental del cultivo de soja en Argentina. Buenos Aires: Centro de Estudios e Investigación Social "Nelson Mandela", 2011.

MINING CLUB. Día del agua. Cerro Vanguardia: Tras la huella del agua. 2013. Disponible en: <http://www.miningpress.com.ar/nota/269442>. Acceso en: 8 mar. 2015.

MINING PRESS ARGENTINA. Mina Martha construirá su propia planta de flotación. 2007. Disponible en: $<$ http://www.miningpress.com.ar/nota/21095/minamartha-construir-su-propia-planta-de-flotacin>. Acceso en: 8 mar. 2015.

MINING PRESS ARGENTINA. Pan American Silver: producción récord. Cuánto aportó Manantial Espejo. 2015a. Disponible en: <http://www.miningpress.com.ar/nota/277484/panamerican-silver-produccion-record-cuanto-aportomanantial-espejo>. Acceso en: 8 mar. 2015.

MINING PRESS ARGENTINA. Goldcorp: cuánto produjo y ganó en 2014. Cerro Negro: oro, costos e impuestos. 2015b. Disponible en: $<$ ww.miningpress.com.ar/nota/277183/goldcorpcuanto-produjo-y-gano-en-2014-cerro-negro-orocostos-e-impuestos>. Acceso en: 8 mar. 2015.

NACIF, F. El litio en Argentina: de insumo estratégico a commodity. Herramienta, Buenos Aires, n. 54, 2014. Disponible en: $<$ http://www.herramienta.com.ar/revistaherramienta-n-54/el-litio-en-argentina-de-insumoestrategico-commodity>. Acceso en: 10 feb. 2015.

NALM. Minera FMC Lithium jamás pagó el canon de agua. 2012a. Disponible en: <http://www.noalamina.org/>. Acceso en: 10 nov. 2014.

NALM. Sin agua para los productores, toda el agua para las megamineras. 2012b. Disponible en: <http://www.noalamina.org/>. Acceso en: 10 nov. 2014.

NALM. Rotunda posición de los pediatras contra la megaminería. 2012c. Disponible en: <http://www.noalamina.org/>. Acceso en: 10 nov. 2014. 
NALM. Minera financia emprendimiento de agua natural en la Patagonia. 2013a. Disponible en: $<$ http://www.noalamina.org/>. Acceso en: 10 nov. 2014.

NALM. Por el consumo minero San Juan colocará medidores de agua a las familias. 2013b. Disponible en: http://www.noalamina.org/>. Acceso en: 10 nov. 2014.

OCMAL. Conflictos mineros en la Argentina, por provincias. Observatorio de Conflictos Mineros de América Latina. 2014. Disponible en: $<$ http://www.conflictosmineros.net/>. Acceso en: 10 nov. 2014

OCMAL. Pan American Silver con el proyecto Manantial Espejo amenaza la vida de Gobernador Gregores. 2015. Disponible en: $<$ http://basedatos.conflictosmineros.net/ocmal_db/ ?page $=$ conflicto\&id $=169>$. Acceso en: 10 mar. 2015.

ODRIOZOLA, Verónica. No todo lo que es oro brilla. Resumen de impactos ambientales de la minería del oro. Buenos Aires: Greenpeace, 2003.

ONU. El derecho al agua y al saneamiento. Ginebra: Organización de las Naciones Unidas, 2010.

OPI SANTA CRUZ. Según el EIA, el yacimiento San José Huevos Verdes cerraría antes del 2012. 2010. Disponible en: $<$ http://opisantacruz.com.ar/home/2010/07/13/seg un-el-eia-el-yacimiento-san-jose-huevos-verdescerraria-antes-del-2012/9537>. Acceso en: 10 nov. 2014.

OPI SANTA CRUZ. Minera Cerro Vanguardia utiliza un volumen de agua diario tres veces superior al que consume Río Gallegos en 24 horas. 2011. Disponible en: <http://opisantacruz.com.ar/home/2009/11/05/min era-cerro-vanguardia-utiliza-un-volumen-de-aguadiario-tres-veces-superior-al-que-consume-todorio-gallegos-cada-24-horas/7788>. Acceso en: 10 nov. 2014.

OROPLATA S.A. Proyecto minero Cerro Negro. Estudio de impacto ambiental "Etapa de explotación". Río Gallegos: IV Jornada de Ambiente y Desarrollo Sustentable, 2010.

PARADA-PUIG, G. El agua virtual: conceptos e implicaciones. Orinoquia, Meta, v. 16, n. 1, p. 6976, 2012.

PENGUE, W. Agua virtual, agronegocio sojero y cuestiones económico-ambientales futuras. Realidad Económica, Buenos Aires, n. 223, p. 58-77, 2006.
PENGUE, W. La economía ecológica y el desarrollo en América Latina. Fronteras, Buenos Aires, n. 7, p. 11-33, 2008.

PENGUE, W. Suelo virtual, biopolítica del territorio y comercio internacional. Fronteras, Buenos Aires, n. 7, p. 12-25, 2010.

PENGUE, Wa. Intangibles ambientales, suelo virtual y nuevas formas de valorización de la naturaleza. Alternativas en discusión frente a la crisis de la civilización. In: PENSADO LEGLISE, M. (Comp.). Territorio y ambiente. Aproximaciones metodológicas. México, D. F: Siglo XXI CCIEMAD, 2012. p. 207-252.

PETROLNEWS.NET. Cerro Vanguardia: la joya de Santa Cruz que busca expandirse. 2009. Disponible en: <http://www.petrolnews.net/noticia.php?r=11672>. Acceso en: 10 mar. 2015.

ROCHA FELICES, A. El agua virtual en el mundo del Siglo XXI. 2012. Disponible en: <http://www.academia.edu/5689326/EL_AGUA_VI RTUAL Y LA HUELLA H\%C3\%8DDRICA EN EL_MUNDOD_DEL_SIGLO_XXI>. Acceso en: 10 ene. 2015.

RODRÍGUEZ PARDO, J. Vienen por el oro, vienen por todo. Las invasiones mineras $\mathbf{5 0 0}$ años después. Buenos Aires: Ciccus, 2009.

SAN JUAN. Consumo de agua. Minas Casposo, Gualcamayo y Veladero. San Juan: Ministerio de Minería de San Juan, 2013a.

SAN JUAN. Estadísticas mineras año 2006. San Juan: Secretaría de Minería de San Juan, 2013b.

SAN JUAN. Estadísticas mineras año 2010. San Juan: Secretaría de Minería de San Juan, 2013c.

SANTOS, M. A natureza do espaço. Técnica e tempo, razão e emoção. São Paulo: Hucitec, 1996a.

SANTOS, M. De la totalidad al lugar. Barcelona, Oikos-Tau, 1996b.

SANTOS, M. Por uma outra globalização. Do pensamemto único ã consciência universal. Rio de Janeiro-São Paulo: Record, 2000.

SANTOS, M.; SILVEIRA, M. L. O Brasil. Território e sociedade no início do século XXI. Rio de Janeiro-São Paulo: Record, 2001.

SCHIAFFINI, H. La inserción de la inversión en la minería en las tendencias socioeconómicas de la Argentina. Theomai, Buenos Aires, n. 10, 2004. Disponible en: <http://revistatheomai.unq.edu.ar/numero10/artschiaffini10.htm Acceso en: 8 nov. 2011. 


\section{REA - Revista de estudos ambientais (Online)}

v.17, n. 2, p. 6-28, jul./dez. 2015

SCRIBANO, A. Bienes comunes, expropiación colonial y depredación capitalista. Estudos de Sociología, Araraguara, 12: 13-36, 2008.

SEOANE, J. Neoliberalismo y ofensiva extractivista. Actualidad de la acumulación por despojo, desafíos de nuestra América. Theomai, Buenos Aires, 26: 1-27, 2012. Disponible en: $<$ http://revista-

theomai.unq.edu.ar/NUMERO $\% 2026 /$ Seoane $\% 20$ -\%20Ofensiva\%20xtractivista.pdf>. Acceso en: 5 jul. 2014.

SILVEIRA, M. L. Um país, uma região. Fim de século e modernidades na Argentina. São Paulo: FAPESP-LABOPLAN-USP, 1999.

SVAMPA, M.; BOTTARO, L.; SOLÁ ÁLVAREZ, M.. La problemática de la minería a cielo abierto: modelo de desarrollo, territorio y discursos dominantes. In: SVAMPA, M; ANTONELLI, M. (Ed.). Minería transnacional, narrativas del desarrollo y resistencias sociales. Buenos Aires: Biblos, 2009. p. 29-50.

VIANO, L. Argentina, uno de los mayores exportadores de agua virtual. Diario La Voz del Interior, 18/02/2013. Disponible en: < http://www.lavoz.com.ar/ciudadanos/argentinauno-mayores-exportadores-agua-virtual>. Acceso en: 13 ene. 2015.

ZIMMER, D.; RENAULT, D. Virtual water in food production and global trade: review of methodological issues and preliminary results. $2003 . \quad$ Disponible en: <http://www.hydroaid.it/FTP/Data_Research/D.\%2 0Zimmer\%20et\%20al-virtual\%20water.pdf>. Acceso en: 7 oct. 2009.

ZOLEZZI, R.; MIRÓ, R.; MUNIZAGA, H. Censo Nacional Minero 2003-2004. Evaluación estadística. Buenos Aires: Secretaría de MineríaFundación Empremin, 2005. 